\title{
A GIS-Based Assessment of Active Tectonics from Morphometric Parameters and Geomorphic Indices of Assam Region, India
}

\section{Laxmi Gupta}

Shiv Nadar University

Navdeep Agrawal

Shiv Nadar University

Jagabandhu Dixit ( $\nabla$ jagabandhu.dixit@snu.edu.in )

Shiv Nadar University https://orcid.org/0000-0002-5450-578X

\section{Subashisa Dutta}

Indian Institute of Technology Guwahati

\section{Research Article}

Keywords: Active tectonics, Assam region, Linear parameters, Areal parameters, Geomorphic indices, IRAT

Posted Date: October 25th, 2021

DOI: https://doi.org/10.21203/rs.3.rs-1012102/v1

License: (c) This work is licensed under a Creative Commons Attribution 4.0 International License. Read Full License

Version of Record: A version of this preprint was published at Journal of Asian Earth Sciences: X on December 1st, 2022. See the published version at https://doi.org/10.1016/j.jaesx.2022.100115. 


\title{
A GIS-Based Assessment of Active Tectonics from Morphometric Parameters and Geomorphic Indices of Assam Region, India
}

\author{
Laxmi Gupta $^{1}$, Navdeep Agrawal ${ }^{1}$, Jagabandhu Dixit ${ }^{1, *}$, Subashisa Dutta ${ }^{2}$
}

\begin{abstract}
${ }^{1}$ Disaster Management Laboratory, Shiv Nadar University, Delhi NCR, Uttar Pradesh 201314, India.
\end{abstract}

${ }^{2}$ Department of Civil Engineering, Indian Institute of Technology Guwahati, Guwahati, Assam 781039, India.

E-mail address of authors: 1g100@snu.edu.in (L.G.); na655@snu.edu.in (N.A.); jagabandhu.dixit@snu.edu.in (J.D.); subashisa@iitg.ac.in (S.D.)

*Corresponding Author: jagabandhu.dixit@snu.edu.in

\section{ABSTRACT}

Assam region lies in the tectonic region of eastern Himalayas and flood plains of River

2 Brahmaputra. The landscape of Assam is formed by the complex integration of the vertical and horizontal movement of the earth's crust and the depositional and erosional process by a river.

4 The frequency of seismic events results in the deformation of landforms and it highly

5 influences the drainage pattern of the area. The analysis of tectonic or neotectonic activity with

6 the help of morphometric parameters and geomorphic indices helps in the identification of

7 hazard-prone areas of the basin. In the present study, the active tectonics of the Assam region

8 is assessed using SRTM DEM data of $30 \mathrm{~m}$ resolution to derive linear and aerial morphometric

9 parameters and eight geomorphic indices of the selected ten basins. The morphometric 10 parameters and geomorphic indices namely, stream length gradient $(S l)$, valley floor width to 
height ratio $(V f h)$, hypsometric curve, hypsometric integral $(H i)$, asymmetric factor $(A f)$, basin shape index $(B S)$, transverse topographic symmetry $(T)$, basin elongation ratio $(B E)$ and stream sinuosity $(S S)$ are calculated for each basin. With the help of GIS, the indices are classified into three tectonic activity classes i.e., from higher to lower and the average of the classes are combined to generate an index of relative active tectonics (IRAT). The four classes of IRAT are defined for the study area as i) very high; Class $1(1.57-1.80)$, ii) high; Class $2(1.81-$ 2.06), moderate; Class $3(2.07-2.26)$ and low; Class $4(2.27-2.30)$. Class 1 of IRAT corresponds to Basin 1 and 6 with a total area of about $47740 \mathrm{~km}^{2}$, basin 2, 4 and 5 falls under Class 2 of IRAT and its total area is $2507 \mathrm{~km}^{2}$, class 3 covers a total area of $17495 \mathrm{~km}^{2}$ of basin 7,8 and 9 and Class 4 IRAT consists of basin 3 and 10 of total area $2090 \mathrm{~km}^{2}$. Results show that the majority of the study area lies in very high to moderate active tectonic zones and these zones are consistent with the presence of major faults and thrusts of the basin area. It can be concluded that the combined approach of GIS-based morphometric and geomorphic study of a region allows in the identification of deformed landforms resulting from active tectonics.

Keywords: Active tectonics; Assam region; Linear parameters; Areal parameters; Geomorphic indices; IRAT

\section{Introduction}

Interaction of the Indian plate with the Eurasian plate led to the rise of the Himalayan which ranges from the North-East region (NER) of India to the Hindu Kush region (Afghanistan) in the west (Ghosh et al., 2018). The Indian plate is active and subducting under the Eurasian Plate at an average rate of $50 \mathrm{~mm} /$ year (Catherine, 2004) which makes the Himalayan belt one of the most seismo-tectonically active regions in the world. The active tectonic region undergoes changes that may either be gradual, fast, or rapid due to underneath tectonic activities. The formation of folds, faults, and basins is evidence of past deformation processes due to tectonic activity (Das et al., 2011). However, the gradual geomorphological 
changes occurring in the region cannot be in the form of readily observable variations in surface deformations and basin drainage patterns and characteristics. These silent changes occurring in any region can be identified by morphotectonic and geomorphic analysis (Taesiri et al., 2020; Divyadarshini and Singh, 2019; Mishra, 2019). In active regions, the basin drainage pattern is sensitive to tectonic activity and processes like folding and faulting which results in drainage geometry, basin asymmetry, river deflection, and accelerated incision (Cox, 1994; Saber et al., 2020). These changes in the river system are also an efficient indicator of differential uplift due to active tectonics (Mishra, 2019).

The geomorphic indices such as hypsometric integral (Strahler, 1952; Daxberger et al., 2014), asymmetric factor (Hare and Gardner, 1985), basin shape (Bull and McFadden, 1977), the ratio of basin elongation (Bull and McFadden, 1977), the width of valley floor to valley height ratio (Bull and McFadden, 1977), index of stream length gradient (Hack, 1973), stream sinuosity (Mueller, 1968) and transverse topography symmetry (Cox, 1994) have been successfully used in active tectonic studies in the past by various researchers ( Das et al., 2011; Mahmood and Gloaguen, 2012; Sharma and Sarma, 2017; Taesiri et al., 2020). Similarly, evaluation of morphometric parameters comprises of stream order and number, bifurcation ratio, the ratio of stream length, drainage density and texture, stream frequency of drainage, drainage texture, circularity ratio, and drainage form factor, are also used as indicators for the assessment of active tectonics of any region (Shukla et al., 2013; Topal 2018; Anand and Pradhan 2019; Bahrami et al., 2020).

Remote sensing and GIS play an important role in data collection and spatial analysis for these indices (Sarp and Duzgun, 2015; Koukouvelas et al., 2018; Alizadeh et al., 2020). This approach is less time-consuming and eliminates the chances of possible errors in data collection by conventional methods of field surveys. In the present study, morphometric and geomorphic indices were extracted from DEM (digital elevation model) for the state of Assam, 
61 NER India, and quantitatively analyzed to evaluate the gradual changes of the basin area due

to active tectonics. Assam lies in the foothills of the north-eastern Himalayan and the flood plains of Brahmaputra River, one of the largest anabranching mega-rivers in the world (Latrubesse, 2008). The region of Assam has high seismicity with complex tectonic and geological settings (Fig. 1a).

The western portion of Assam is sandwiched between the MFT and Dauki Fault (forming Shillong Plateau in the south of the study area) while the eastern portion is sandwiched between MFT and Naga thrust with Mishmi thrust trending NW-SE in the NE which led to the formation of flood plains of alluvial deposits from east to west except for the central part of the state (Fig. 1b). The central part also comprises major faults like the Kopili fault and Dighalpani-Kakijan fault with extensions of the Dauki fault and Naga thrust, forming the separate drainage basin of several rivers other than the Brahmaputra River basin (Panda et al., 2018; Bahuguna and Sil, 2020).

In the past, this region has experienced many significant earthquakes as high as $\mathrm{Mw} 8$ due to the activity of these tectonic features. The continuous activity of tectonic and movement has affected the morphology of the Himalayan foreland (Devi, 2007; Raghukanth et al., 2011; Dixit et al., 2016; Biswas and Paul, 2021). Therefore, an attempt was made to evaluate the tectonic activity of the entire state of Assam based on morphometric and geomorphic indices using remote sensing data and a GIS-based approach. Similar approaches have been successfully used in other active tectonic regions such as Nagaland India (Longkumer et al., 2018), Hindu Kush Afghanistan (Mahmood and Glaoguen, 2011), Siwalik Hills of Himalayans (Singh and Chaudhri, 2020), Qianhe river basin North China (Zhang et al., 2019), Greater Antilles North America (Rodriguez et al., 2017), Coasts of Mediterranean Sea Spain (Silva et al., 2003) and NW Iran (Saber et al., 2018). 

sections.

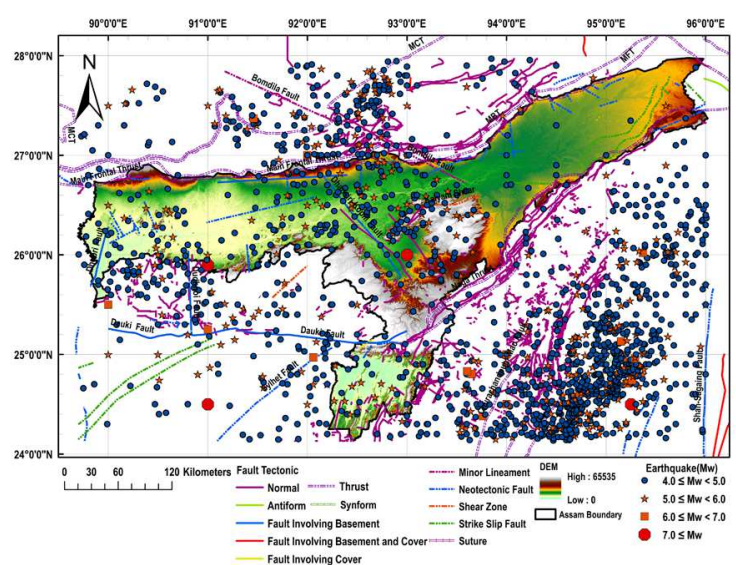

(a)

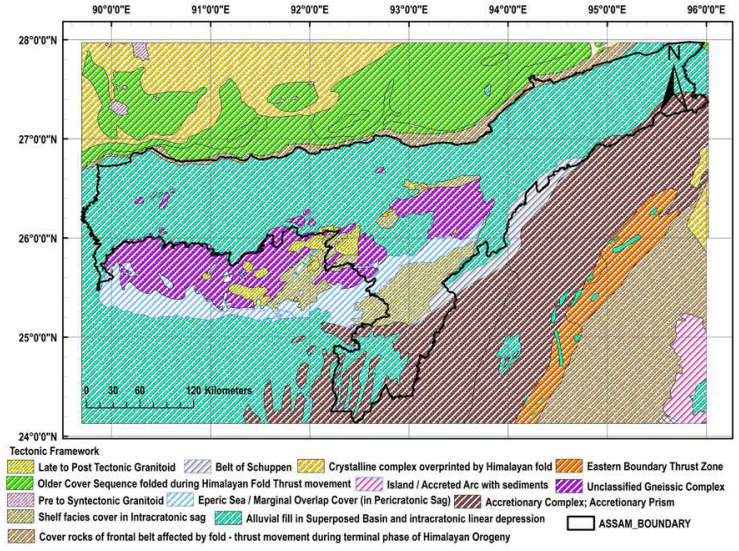

(b)

Fig. 1. Map of the study area and its surroundings showing (a) major fault tectonics, seismicity, and elevation, and (b) geotectonic framework.

\section{Methodology}

The present study aims at GIS (Geographic Information System) based determination of morphometric parameters and geomorphic indices to assess the tectonic activity of the Assam region. The study area consists of Brahmaputra valley and Barak valley and it is further divided into 10 basins of stream order varies from $1^{\text {st }}$ to $7^{\text {th }}$ order (Strahler, 1957). For the present study, the basin having a stream equal to and greater than 3 is considered for the quantification of morphometric parameters and geomorphic indices. The morphometric parameters (linear and areal parameters) and geomorphic indices are extracted with the help of 1 arc second Shuttle Radar Topography Digital Elevation Model (SRTM DEM) data of 30m resolution (https://earthexplorer.usgs.gov/), earthquake data (Bhukosh-Geological Survey of India; United States Geological Survey; International Seismological Centre) and tectonic framework of the study area (Bhukosh-Geological Survey of India). With the help of the DEM layer with $30 \mathrm{~m}$ resolution, two primary layers i.e., watershed and river vector layers are 


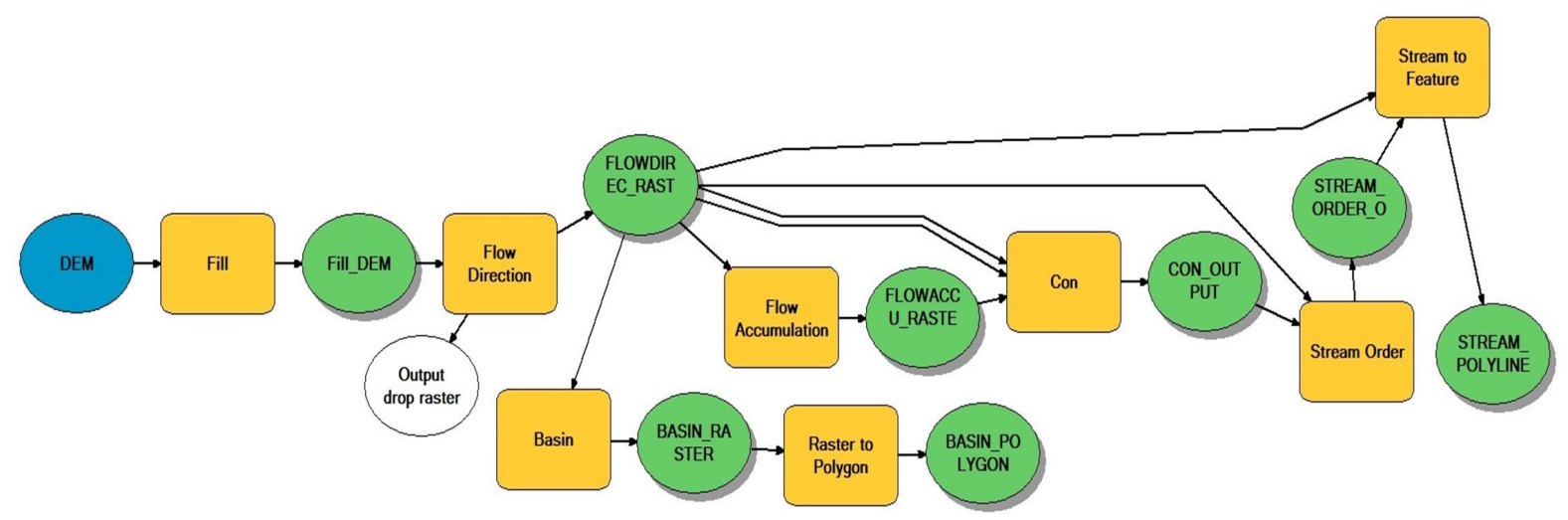

Fig. 2. GIS model for the extraction of basins and streams using DEM data.

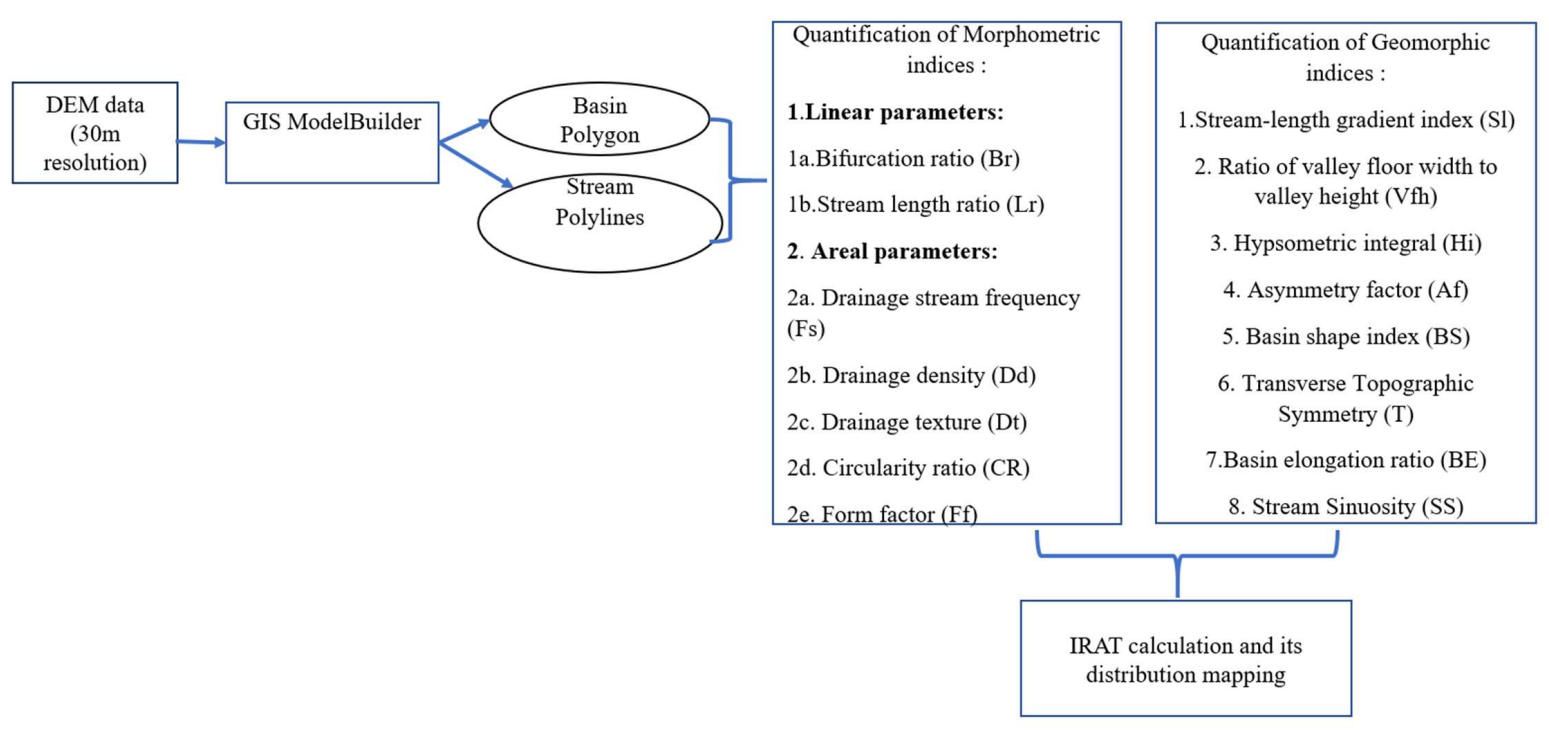

Fig. 3. Schematic diagram of the methodology adopted in the study.

112 Each layer is classified into three classes based on their tectonic activity and finally, IRAT

113 (Indices of relative active tectonics) is calculated to identify the tectonically active region with the help of morphotectonic indices (Cheng et al., 2016; Gu et al., 2019; Bhattacharjee and 
Mohanty, 2020; Pei et al., 2021). The flowchart of the adopted methodology is illustrated in the schematic diagram in Fig. 3 and details of different morphometric and geomorphic indices

117 are presented in the upcoming section of this study.

\section{Evaluation of Indices}

Morphometric and geomorphic indices can be defined as a tool that helps in the determination of deformational process as well as the evolution of a landform due to dynamic 121 processes (Raj, 2012; Bhat et al., 2020). These indices act as an indicator of anomalies in the 122 drainage system that arises due to tectonic activity and thus differentiate tectonically active zones of the region. In the present study, 10 basins of the Assam region are delineated and morphometric and geomorphic indices are evaluated for each basin. Each index is categorized into three tectonic classes based upon the range of values. The schematic representation of the parameters of geomorphic indices is shown in Fig. 4.
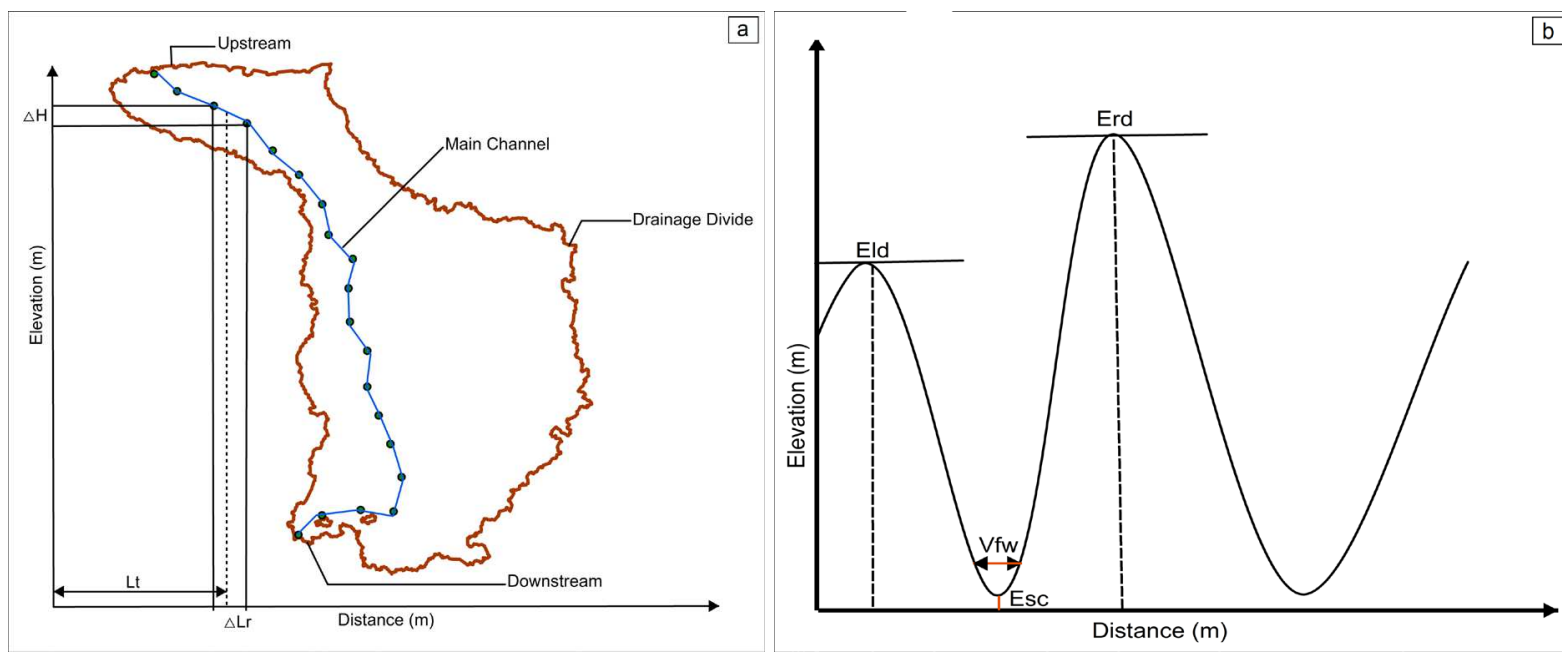

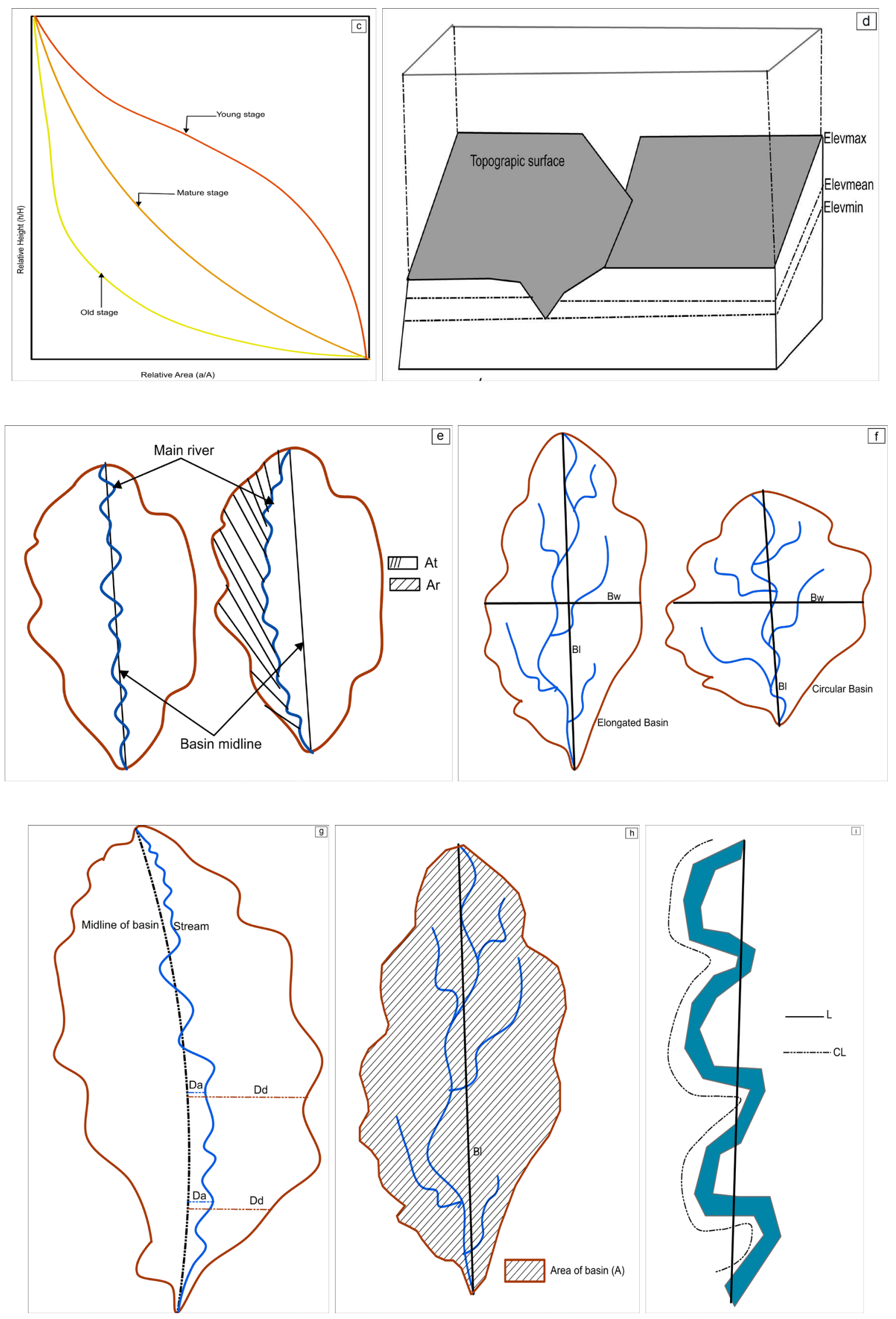
Fig. 4. Parameters of Geomorphic Indices (a) Stream length gradient ( $S l$ ), (b) Valley floor width to height ratio (Vfh), (c) Hypsometric curve, (d) Hypsometric integral (Hi), (e) Asymmetric factor $(A f)$, (f) Basin shape index $(B S)$, (g) Transverse topographic symmetry $(T)$, (h) Basin elongation ratio $(B E)$, (i) Stream sinuosity $(S S)$.

Finally, the index of relative active tectonics (IRAT) is calculated and classified into four tectonic activity classes for the entire region by taking the arithmetic mean of morphometric and geomorphic indices classes.

\subsection{Morphometric Indices}

\subsubsection{Linear parameters}

The linear parameters are used to evaluate the evolution one dimensional characteristic of the drainage basin. In the present study, the linear parameters considered are Stream order $(U)$, stream number $(N u)$, bifurcation ratio $(B r)$, and stream length ratio $(L r)$. Among the four linear parameters, the bifurcation ratio $(B r)$ and stream length ratio $(L r)$ are the most significant ones. The highest stream order of the basin is of seventh order, the stream order of each basin is calculated (Table 1 and Fig. 5)

The Bifurcation ratio is calculated by the equation

$$
B r=\frac{N_{u}}{N_{u+1}}
$$

$N_{u}$ is the number of streams of a particular order and $N_{u+1}$ is the number of streams of higher-order (Horton, 1945). The high values of $B_{r}$ represent a young stage of the basin and low values signify the mature development stage of the basin.

The range of $B r$ values in the present study varies between 1.25 (Basin 7) and 3.58 (Basin 5). The calculated values are divided into three classes (Anand and Pradhan, 2019): Class 1(3.58 - 2.32), Class $2(2.31-2.00)$, and Class $3(<2.00)$. 


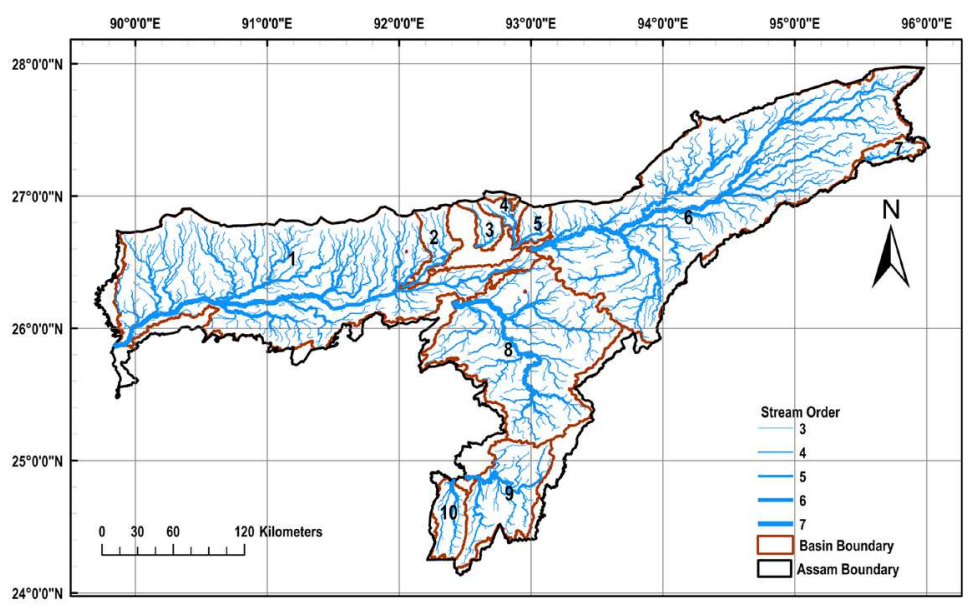

Fig. 5. Stream order of the basins.

Stream length ratio $(L r)$ is defined as the linear parameter of a basin and it is expressed as the ratio of the total length of a stream of specific higher stream order to the total length of stream of next lower order as given by the equation,

$$
L r=\frac{L_{u}}{L_{u-1}}
$$
lower order (Sreedevi et al., 2005). The value of $L r$ of a basin depends on the prevailing slope and topographic conditions. The surface flow discharge and erosional stage of the basin are also defined by the stream length ratio. In the present study, the minimum value of $L r$ is 0.48 (Basin 8) and 2.14 (Basin 5), and the classification of Lr are as follows (Anand and Pradhan, 2019): Class 1 (2.14 - 1.11), Class $2(1.12-0.55)$, and Class $3(<0.55)$.

After the classification of values into three tectonic activity classes i.e., Class 1 (high), Class 2

167 (moderate), and Class 3 (low) for the two linear parameters (Table 1), the average class value of the two linear parameters is taken and divided into three classes of tectonic activity as Class 1, 2 and 3 (Table 3 and Fig. 10a).

\subsubsection{Areal parameters}


172 frequency $\left(F_{s}\right)$, drainage texture $\left(D_{t}\right)$, circularity ratio $(C R)$, and form factor $\left(F_{f}\right)$. In the present

173

174 study, the above-mentioned areal parameters are evaluated for the analysis of erosional processes taking place in the basin.

The drainage density $\left(D_{d}\right)$ of the basin can be explained mathematically as:

$$
D d=\frac{\sum L_{t}}{A}
$$

where $L_{t}$ denotes the length of the total stream and $A$ is the total area of the basin (Horton, 1945). The factor $D_{d}$ depends on the geological condition, rainfall intensity, type of soil, and vegetation (Horton, 1945). The minimum and maximum value of drainage density in the study are 0.19 (Basin 10) and 0.23 (Basin 1) respectively and the classes are (Anand and Pradhan, 2019): Class $1(0.23-0.208)$, Class $2(0.207-0.20)$ and Class $3(<0.200)$.

Drainage Stream frequency $\left(F_{s}\right)$ is calculated for each basin with the help of equation

$$
F s=\frac{\sum N_{u}}{A}
$$

$N_{u}$ is the sum of segments of stream of all orders in the basin and A represents the total area of the basin (Horton, 1945). The range of $F_{s}$ lies between 0.131 to 0.169 for Basin 3 and Basin 10 respectively. To determine the tectonic activity class of each basin, the values obtained in the study are grouped into high, moderate, and low classes as $0.169-0.145$ (Class 1), $0.144-0.140$ (Class 2), and $<0.140$ (Class 3) respectively.

The drainage texture $\left(D_{t}\right)$ of a basin can be defined by the equation

$$
D t=\frac{\sum N_{u}}{P}
$$



perimeter of the basin (Horton, 1945). The range of $D_{t}$ calculated for the ten basins varies from 0.354 (Basin 4) to 2.638 (Basin 6) and the classification of the $D_{t}$ values are: Class $1(2.638-$ 2.109), Class $2(2.108-0.536)$, and Class $3(<0.536)$. impermeability, and high relief conditions whereas lower values indicate high infiltration rate, permeable lithological conditions, and presence of lower relief (Shukla et al., 2013). evaluated for the identification of the shape of the drainage basin. The circularity ratio $(C R)$ of the basin is calculated by the equation

$$
C R=\frac{4 \pi A}{P^{2}}
$$

Where $A$ and $P$ represent the area and perimeter of the basin respectively. The circulatory ratio $(C R)$ is influenced by the geology, slope, and land cover of the selected area. The circulatory ratio $(C R)$ calculated in this study lies from 0.122 (Basin 4) to 0.301 (Basin 10). The values of $C R$ are classified into three different active tectonic classes (Anand and Pradhan, 2019): Class 1(0.122 - 0.207), Class $2(0.208-0.264)$, and Class $3(0.265-0.301)$ correspond to high, low, and moderate respectively. The high value of $C R$ denotes a circular basin that tends to evolve into an elongated basin.

$$
F f=\frac{A}{L_{b}^{2}}
$$


213 the value of $F_{f}$ ranges from 0.178 (Basin 2) to 0.364 (Basin 8) and the values are further grouped

214 into high to low tectonic classes as $(0.178-0.207),(0.208-0.330)$, and $(>0.330)$ belongs to

215 Class 1, Class 2 and Class 3, respectively (Anand and Pradhan, 2019). The low form factor

216 values mainly describe the elongated basins which are structurally and tectonically controlled.

(moderate), and Class 3 (low) as per the tectonic activity (Table 1) and their average values of 219 class are determined and categorized into high, medium and low class represented as Class 1,

220 Class 2 and Class 3 respectively (Table 3 and Fig. 10b).

Table 1 Morphometric Indices parameters.

\begin{tabular}{|c|c|c|c|c|c|c|c|c|}
\hline \multirow{2}{*}{$\begin{array}{l}\text { Basin } \\
\text { no }\end{array}$} & \multirow[b]{2}{*}{$U$} & \multicolumn{2}{|c|}{ Linear Parameters } & \multicolumn{5}{|c|}{ Areal Parameters } \\
\hline & & $B r$ & $L r$ & $F s$ & $D d$ & $D t$ & $C R$ & $F f$ \\
\hline 1 & 7 & 2.19 & 0.55 & 0.14 & 0.23 & 2.11 & 0.12 & 0.19 \\
\hline 2 & 5 & 1.59 & 0.72 & 0.14 & 0.22 & 0.48 & 0.13 & 0.18 \\
\hline 3 & 5 & 2.11 & 0.53 & 0.13 & 0.21 & 0.44 & 0.21 & 0.35 \\
\hline 4 & 5 & 1.30 & 1.11 & 0.14 & 0.20 & 0.35 & 0.12 & 0.33 \\
\hline 5 & 5 & 3.58 & 2.14 & 0.14 & 0.20 & 0.54 & 0.27 & 0.36 \\
\hline 6 & 7 & 2.00 & 0.50 & 0.14 & 0.21 & 2.64 & 0.17 & 0.21 \\
\hline 7 & 5 & 1.25 & 0.76 & 0.15 & 0.19 & 0.53 & 0.27 & 0.27 \\
\hline 8 & 7 & 2.32 & 0.48 & 0.14 & 0.19 & 1.98 & 0.21 & 0.36 \\
\hline 9 & 6 & 2.44 & 0.52 & 0.14 & 0.20 & 1.23 & 0.22 & 0.29 \\
\hline 10 & 6 & 1.45 & 0.56 & 0.17 & 0.19 & 0.99 & 0.30 & 0.35 \\
\hline
\end{tabular}




\subsubsection{Stream-length gradient index (Sl)}

When the river and streams flow through their course, a dynamic equilibrium is reached

226

227

228

229

230

231

232

233

234

235

236

237

238

when erosional processes equal the upliftment of landmass and as a result, the river system tends to form a concave longitudinal profile (Hack, 1973; Schumm et al., 2000). This stable profile of the river system tends to deviate due to various factors mainly lithological, climatic, or tectonic. To evaluate the influence of environmental factors on the longitudinal profile of the river and streams, $S l$ index can be calculated. It is a quantitative approach that is based on the depositional and erosional processes of a drainage system and also determines the reach of equilibrium by the streams. It is found that the $S l$ index is used in the evaluation of the tectonic activity of a region, an area with soft rocks having high $S l$ values indicates the occurrence of recent tectonic activity, and high $S l$ values also represent the presence of river flow through the strike-slip faults. Mathematically $S l$ index can be defined as

$$
S l=\left(\frac{\Delta H}{\Delta L_{r}}\right) * L_{t}
$$

$\triangle H$ is the elevation change, $\triangle L_{r}$ is the length of the reach and $L_{t}$ is the horizontal distance from the divide of the watershed reach midpoint (Fig. 4a). 

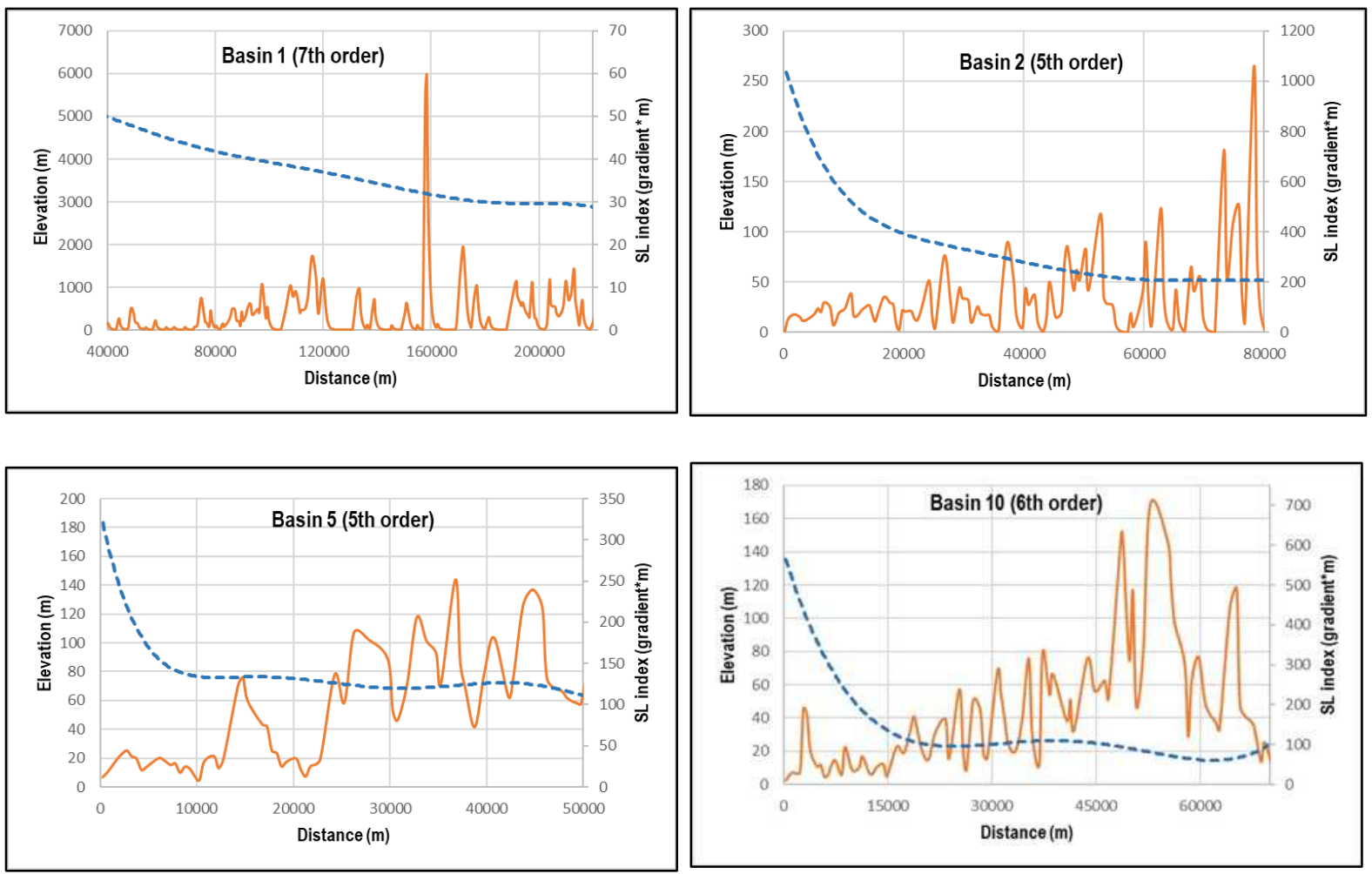
selected basins.

In this study, the value of $S l$ is calculated along the river and stream length (Fig. 6), and the standardized values are estimated for the classification. The range of $S l$ values for the 10 basin lies between 62.58 (Basin 4) to 466.87 (Basin 9) and classified into three classes (Mahmood and Gloaguen, 2012), in Fig. 10c, as Class 1 (>250), Class 2 (250 - 120) and Class $3(<120)$.

\subsubsection{Valley floor width to valley height ratio (Vfh)}

Valley floor width valley height ratio $(V f h)$ is one of the important geomorphic indices

251 which is used for the discrimination between $\mathrm{V}$-shaped and U-shaped valleys and also gives a representation of active tectonics of a region (Bull and McFadden, 1977). Mathematically the index can be defined as: 


$$
V f h=\frac{2 V f_{w}}{\left(E_{r d}-E_{s c}\right)+\left(E_{l d}-E_{s c}\right)}
$$

where $V f_{w}$ is the valley floor width, $E_{s c}$ is the average elevation of the valley floor, $E_{r d}$

and $E_{l d}$ are the elevations of the right and left valley divide facing in the downstream direction respectively (Fig. 4b).

The $V f h$ index gives an indication of incision and uplift along a river channel. The low value of $V f h$ signifies a higher incision and uplift rate resulting in deep V-shaped valleys due to the dominance of tectonic activity over erosional processes. The high value of $V f h$ corresponds to a U-shaped valley or flat-floored valleys mainly formed due to erosional processes at bed level. For the present study, cross-sections are drawn from the DEM data at a given distance, and the cross-sections are shown in (Fig. 7).

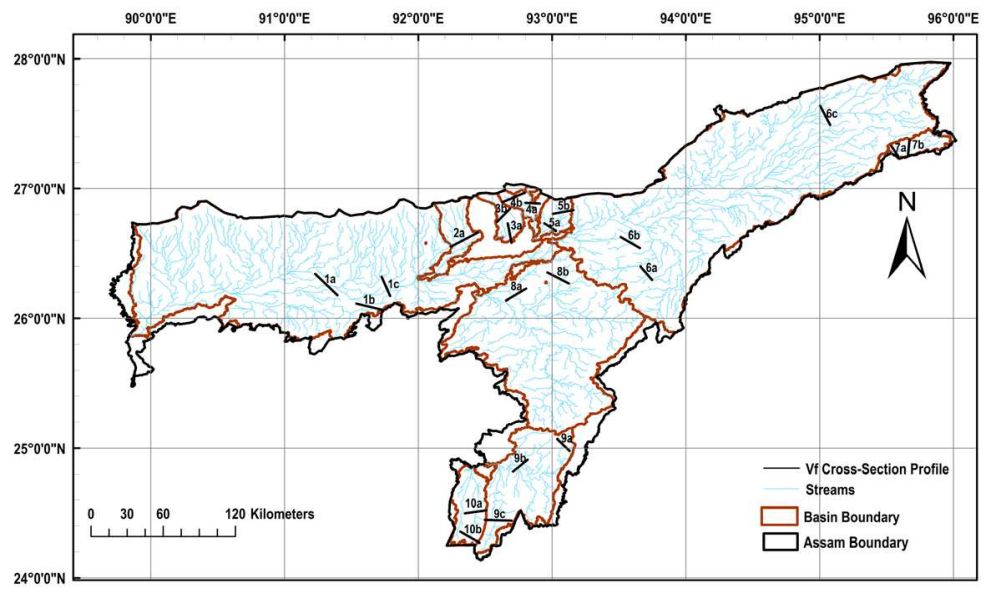

Fig. 7. Cross-sections for calculation of the ratio of Valley floor width to height $(V f h)$.

The average value of $V f h$ is calculated for the basins where more than one cross-section is drawn and the average values are divided into three active tectonic class Class $1(0.260$ 0.660), Class $2(0.661-0.900)$, and Class 3 (>0.900) describing the high, medium and low tectonic activity of the basins, respectively (Mahmood and Gloaguen, 2012). The results indicate that the lowest value of $V f h$ is 0.260 for basin 7 and the highest value is 8.540 for basin 1, which describes that shape of basin 1 and basin 7 are comprised of U- and V-shaped valleys 
respectively. For basins 2,4,5,7 and 10, the value of $V f h$ is less than 1 and the values are more than 1 for basins 1,3,6,8, and 9 (Fig. 10d).

\subsubsection{Hypsometric integral (Hi) and hypsometric curve}

Hypsometric integral and hypsometric curves explain the erosional and depositional processes occurring in a drainage basin that is linked with the tectonic evolution and geomorphology of the basin. The $H i$ index is defined as the elevation distribution of a given area of the drainage basin and it is represented by the area that lies below the hypsometric curve expressing the total volume of the non-eroded basin.

Hypsometric curves are graphical representation which is obtained by plotting the proportion of total elevation of basin against the proportion of total basin area (Fig. 8). Based on the shape of the hypsometric curve, the stages of the basin can be classified as (i) concave curve signifies old eroded basin region, (ii) S-shaped curve denotes basin regions that are moderately eroded, and (iii) convex hypsometric curve represent a young stage of the basin that are slightly eroded (Fig. 4c) (Strahler, 1952). The values of $H i$ ranges from 0 to 1 and can be calculated as:

$$
H i=\frac{\left(\text { Elev }_{\text {mean }}-\text { Elev }_{\text {min }}\right)}{\left(\text { Elev }_{\text {max }}-E l e v_{\text {min }}\right)}
$$

Elev $_{\text {mean }}$, Elev $_{\min }$, and Elev max $_{\text {ax }}$ are the mean, minimum and maximum elevation of the basin respectively (Fig. 4d).

For the calculation of $H i$, Daxberger's methodology is adopted using ArcGIS 10.5 (Daxberger et al., 2014). The high $H i$ value is an indication of a younger landscape that is formed due to recent tectonic activity whereas low $H i$ value is related to older landforms that are more eroded but less affected by tectonic activity recently.

The result of $\mathrm{Hi}$ for the 10 basins are grouped into three classes (Mahmood and Gloaguen, 2012): Class $1(0.200-0.287)$, Class $2(0.100-0.199)$, and Class $3(<0.100)$ 

is lowest for basin 9 (0.020) and highest for basin 4 (0.287).

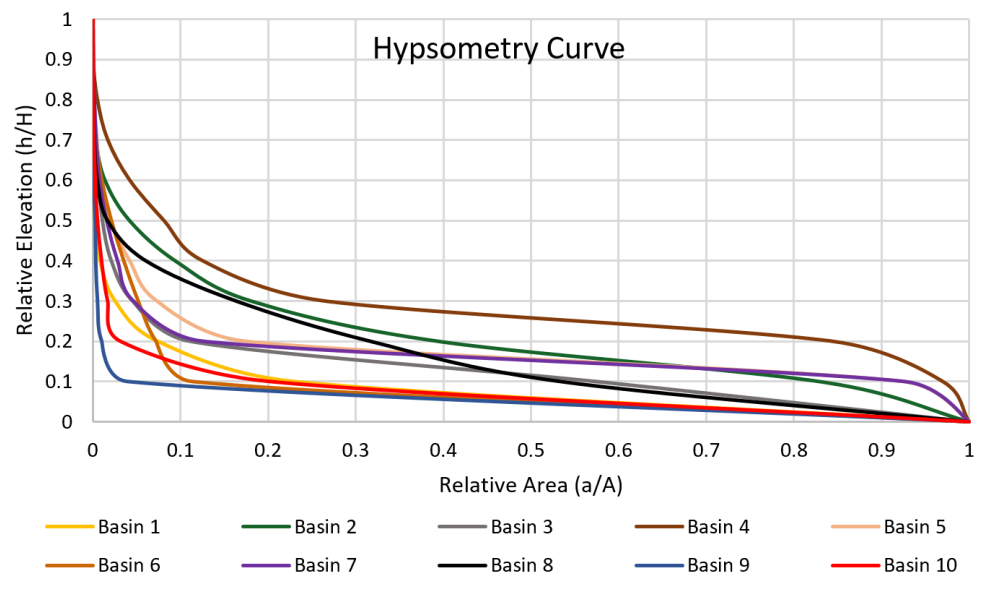

Fig. 8. The hypsometric curve of 10 basins of the study area.

300

301

302

\subsubsection{Asymmetric Factor (Af)}

Asymmetry factor $(A f)$ is an essential parameter of basin drainage and determines the existence of tectonic tilting of the basin. The tilting in the basin arises due to the tectonic disturbance and it causes deviation of the main river channel from the midline of the basin to the direction in which tilting has occurred. It can be applied at basin drainage scale as well as over a large area and mathematically it can be expressed as

$$
\text { Af }=\left(\frac{A_{r}}{A_{t}}\right) * 100
$$

$A_{r}$ denotes the basin area to the right of the mainstream in the downstream direction and the total area of the basin is $A_{t}$ (Fig. 4e) (Hare and Gardner, 1985). The value of $A f$ greater than or smaller than 50 indicated the presence of tectonic activity or lithological control and $A f$ close to 50 signifies that no or less tilting is present. Before the calculation of the Af parameter for the 10 basins of the study area, the thalweg line is drawn for each basin and the area on both sides of the thalweg line is determined in the GIS environment. The tilting direction of the basin is identified (Fig. 9) and the descriptive value of $A f$ is considered equal to the absolute value of $(A f-50)$. 


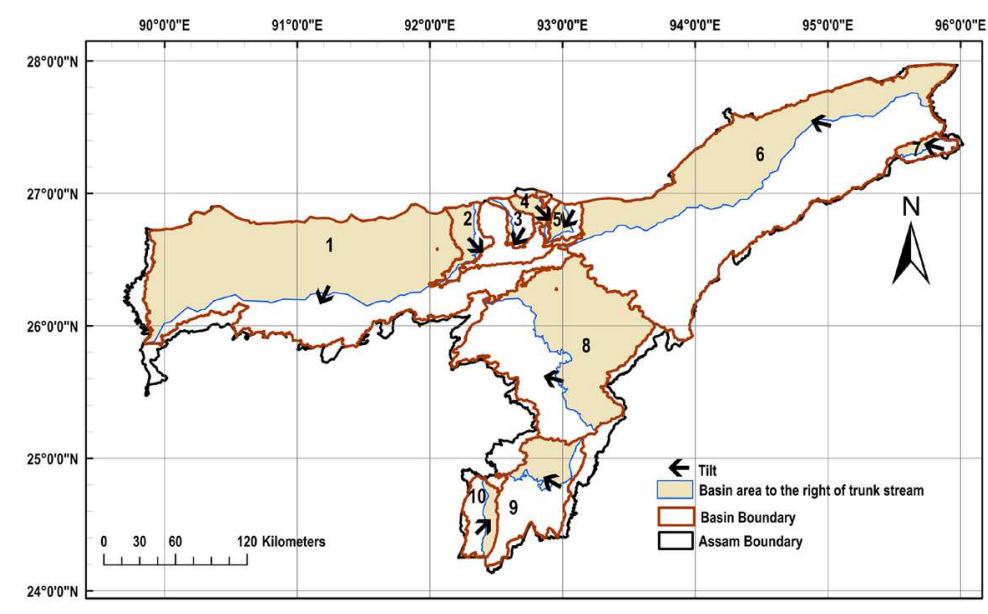

Fig. 9. The direction of the titling of basins in the study area.

\subsubsection{Drainage Basin shape index (Bs)}

In an active tectonic area, the basin exhibits an elongated shape and it tends to attain a circular shape with topographic evolution or decreasing of tectonic activity (Bull and McFadden, 1977). This transformation takes place because in an active tectonic area the width of the drainage basin is narrow near the mountain front and the energy of the stream is primarily directed in the direction of downcutting. In contrast, the areas that lack the continuing rapid uplift favor the widening of the drainage basin upstream of the mountain front (RamírezHerrera, 1998). The basin shape index can be expressed as

$$
B s=\frac{B_{l}}{B_{w}}
$$

where $B_{l}$ defines the total distance measured from the source to the mouth of the basin and $B_{w}$ is the maximum measured width of the basin (Fig. $4 \mathrm{f}$ ).

The elongated basins have high $B S$ values and it is related to higher tectonic activity and the circular basins having very low tectonic activity exhibit low $B S$ value. So, the values 
334 of $B s$ can be used as an indicator of the rate of tectonic activity of a basin. In the present study,

$335 B s$ are calculated using the DEM data and the results are classified (Taesiri et al., 2020) into

336 Class 1 (2.450 -3.080); Class 2 (1.830 - 2.449), and Class $3(<1.830)$ denoting high, moderate,

337 and low active tectonics of the basins respectively. The range of $B s$ values lies between 1.210

338 (Basin 8) to 3.080 (Basin 1) and spatially distributed (Fig. 10g).

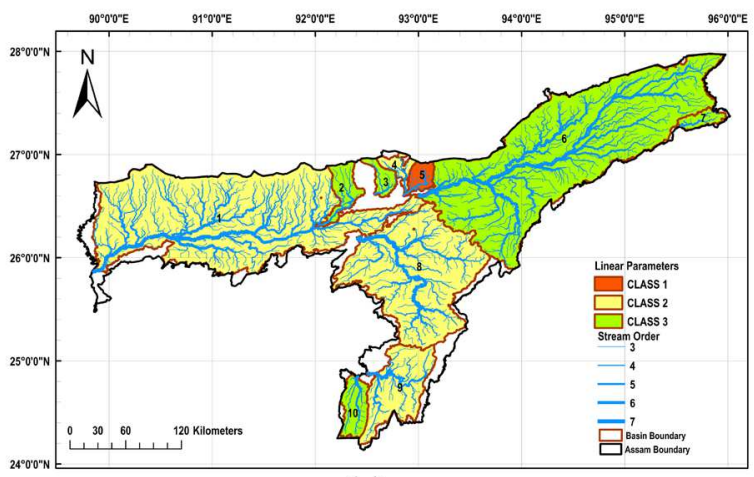

(a)

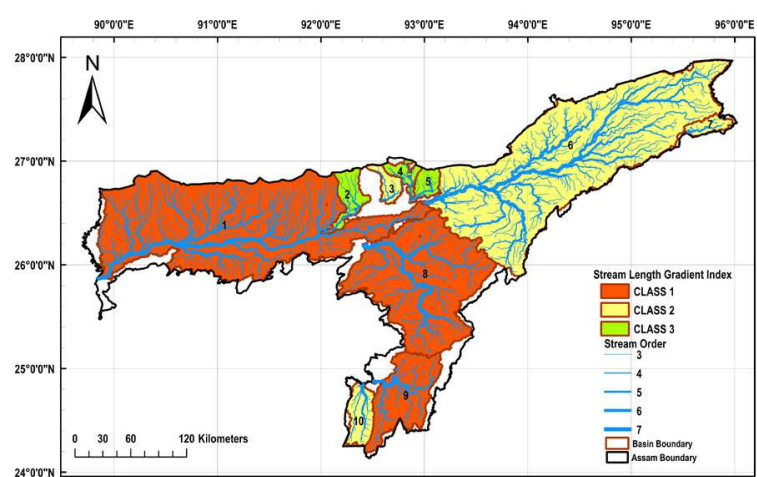

(c)

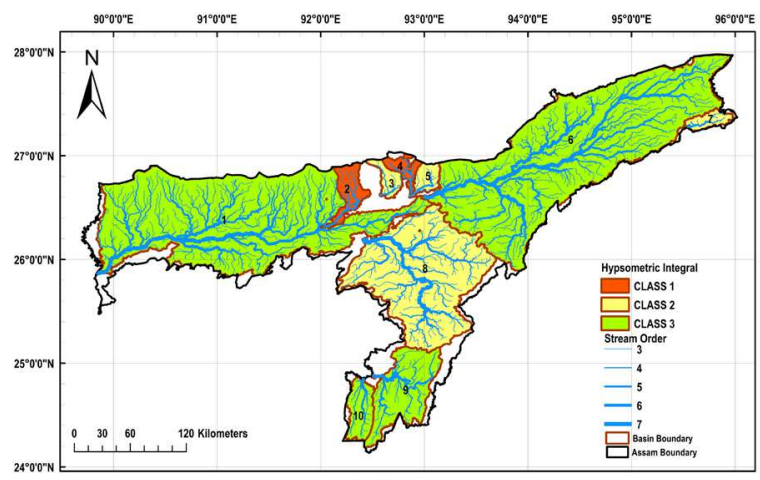

(e)

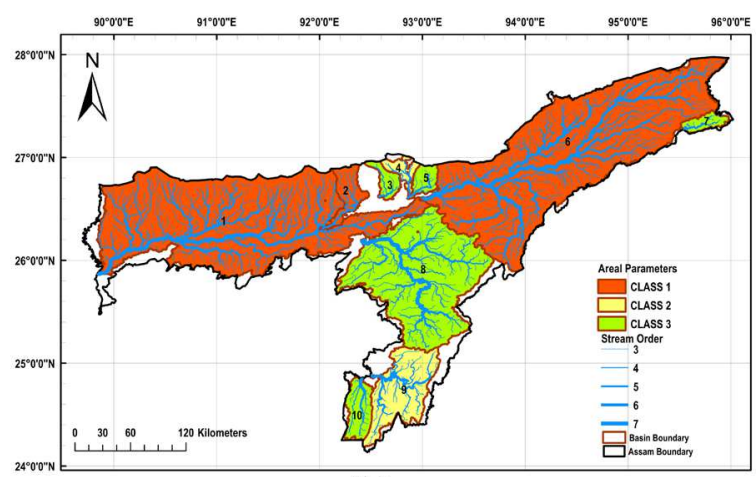

(b)

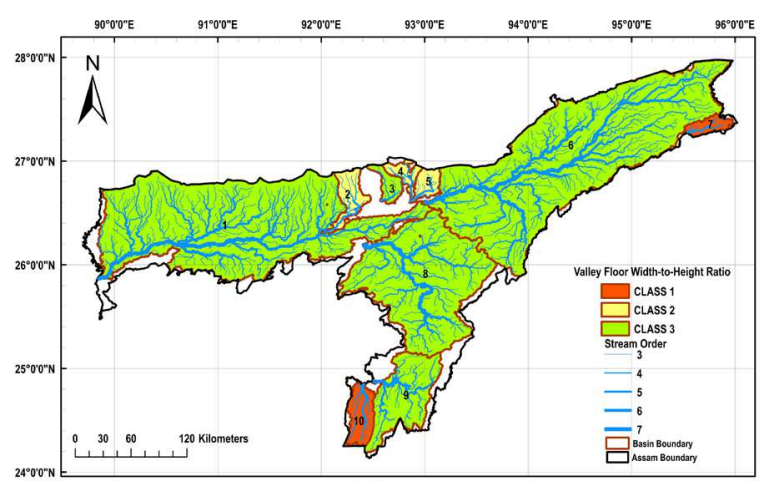

(d)

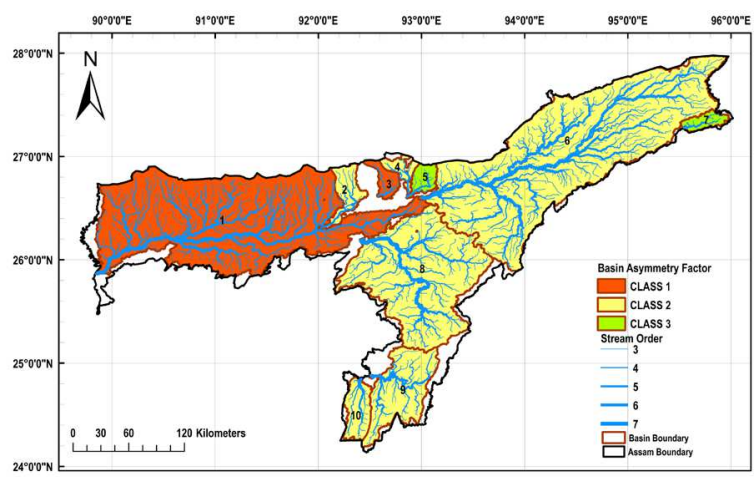

(f) 


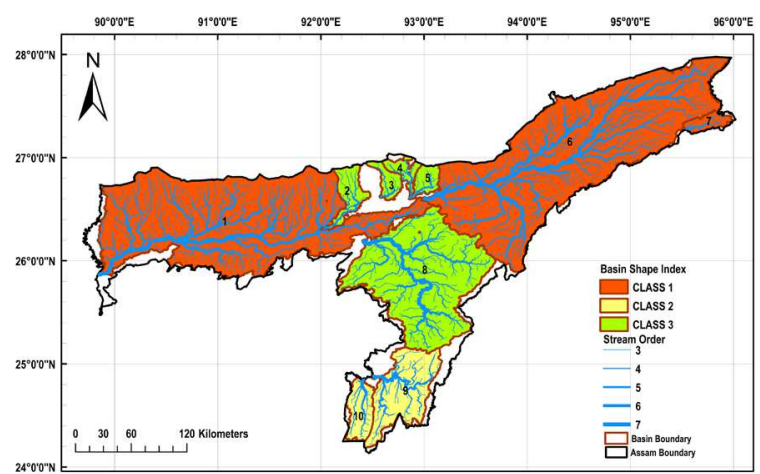

(g)

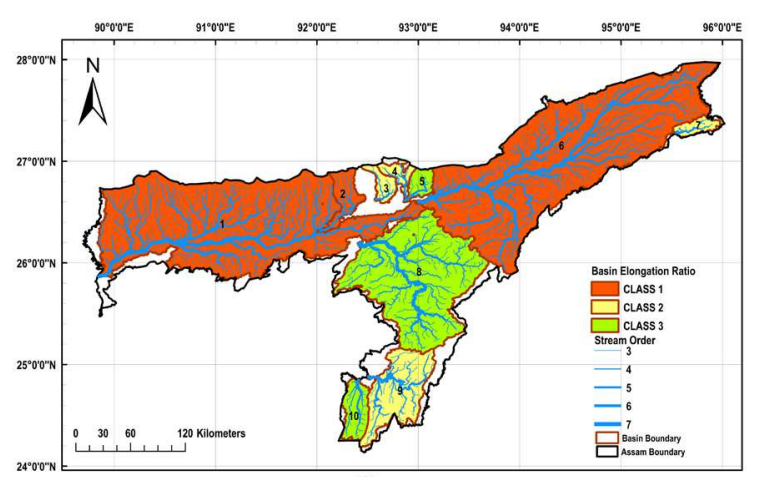

(i)

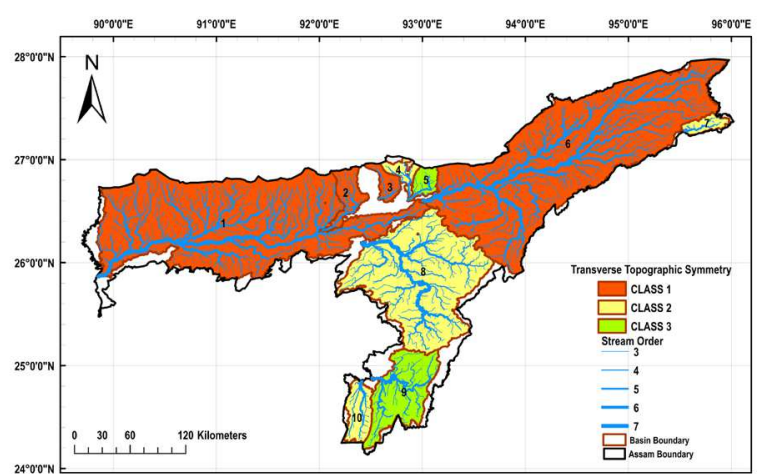

(h)

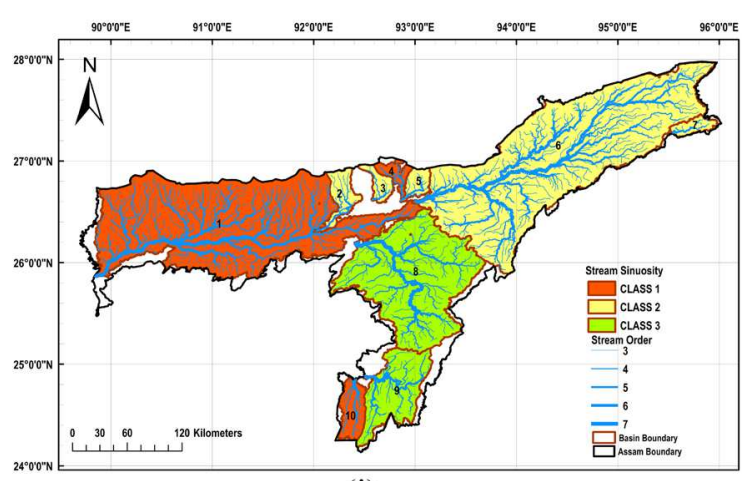

(j)

Fig. 10. Spatial distribution of (a) Linear parameters (b) Areal parameters (c) Stream length gradient $(S l)$, (d) Valley floor width to height ratio ( $V f h)$, (e) Hypsometric integral (Hi), (f) Asymmetric factor $(A f),(\mathrm{g})$ Basin shape index $(B S)$, (h) Transverse topographic symmetry, (i) Basin elongation ratio $(B E)$, (j) Stream sinuosity $(S S)$.

\subsubsection{Transverse topographic symmetry $(T)$}

The transverse topographic symmetry $(T)$ is calculated for measuring the tilting of the basin due to the presence of tectonic activity. $T$ index is calculated based on the symmetry vector data of the basin which includes deflection of the meander belt from the midline of the basin. The value of $T$ can be calculated by the given equation and it ranges from 0 to 1 .

$$
T=\frac{D_{a}}{D_{d}}
$$

In the above equation, $D_{a}$ is defined as the deflection of the channel of the stream from the basin midline and $D_{d}$ is the distance between basin midline and basin divide (Fig. $4 \mathrm{~g}$ ). 

basins and symmetric basin $T=0$ and asymmetric basin $T>0$ (Cox, 1994). The minimum value for Basin 3. The $T$ values are classified into three classes (Taesiri et al., 2020) as follows Class $1(0.380-0.540)$, Class $2(0.230-0.379)$ and Class $3(<0.230)$ from high to low tectonic activity (Fig. 10h).

\subsubsection{Basin elongation ratio (BE)}

Basin elongation ratio is a significant geomorphic index that supports the neotectonic activity of a drainage basin. It is a dimensionless quantity, determined as the ratio of the diameter of a circle which has an equal area as the of the basin under consideration and the maximum basin length (Bull and McFadden, 1977). The area of each basin and its maximum length is calculated in the ArcGIS 10.5 and the value of BE is calculated by the given expression,

$$
B E=\frac{2(A / \pi)^{0.5}}{B_{l}}
$$

where $A$ and $B_{l}$ are the area and maximum length of the basin, respectively (Fig. 4h). between 0.50 to 0.75 are considered as slightly active and more than 0.75 falls under inactive tectonic area. The lowest and highest value of $B E$ obtained in the study is 0.477 and 0.684 suggesting that the study area of the basins falls under tectonically active to a slightly active class. The values of BE obtained in the present study are divided into three classes (Mahmood and Gloaguen, 2012) of high, moderate, and low tectonic activity as Class $1(0.477-0.502)$,

\subsubsection{Stream Sinuosity (SS)}


In the assessment of the tectonic activity of an area, stream sinuosity can also be

381

382

383

384

385

386

387

388

389

390

391

392

393

394

considered as an important indicator. The index of stream sinuosity can be obtained by the ratio of the length of a stream i.e., the curvilinear path and length of the straight line joining the two ends of the selected channel reach. Mathematically, it can be written as,

$$
S S=\frac{C L}{L}
$$

where, $C L=$ Length of stream channel and $L=$ Straight line joining the two ends of the channel (Fig. 4i).

If the value of $S S$ is high, it indicates that the river is tectonically stable and it is closer to equilibrium whereas a low value of $S S$ denotes that the basin area is active (Mueller 1968).

The value of $S S<1.05$ represent tectonic active, $1.05<S S<1.5$ are semi-active and $S S>1.5$ are inactive (Bull and McFadden 1977). In the present study, the minimum value of the $S S$ index is 1.114 for basin 10 and the maximum value is 2.102 for basin 9 . The values are classified into three classes (Taesiri et al., 2020), i.e., Class 1 (1.114-1.171), Class 2 (1.172 1.450), and Class $3(1.451-2.102)$ and spatially distributed (Fig. 10j).

Table 2 Geomorphic indices parameters.

\begin{tabular}{|l|l|l|l|l|l|l|l|l|}
\hline Basin & Sl & Vfh & Hi & Af & $B S$ & $T$ & $B E$ & $S S$ \\
\hline 1 & 270.94 & 8.54 & 0.09 & 19.15 & 3.08 & 0.41 & 0.49 & 1.17 \\
\hline 2 & 119.71 & 0.90 & 0.21 & 17.33 & 1.76 & 0.44 & 0.48 & 1.30 \\
\hline 3 & 121.17 & 1.15 & 0.13 & 26.68 & 1.63 & 0.54 & 0.66 & 1.41 \\
\hline 4 & 62.58 & 0.70 & 0.29 & 13.96 & 1.49 & 0.24 & 0.65 & 1.12 \\
\hline 5 & 85.32 & 0.90 & 0.16 & 0.14 & 1.58 & 0.08 & 0.68 & 1.45 \\
\hline 6 & 190.84 & 1.61 & 0.09 & 11.83 & 2.53 & 0.41 & 0.50 & 1.22 \\
\hline 7 & 172.87 & 0.26 & 0.16 & 3.40 & 2.65 & 0.32 & 0.58 & 1.31 \\
\hline
\end{tabular}




\begin{tabular}{|l|l|l|l|l|l|l|l|l|}
\hline 8 & 624.21 & 4.90 & 0.16 & 9.81 & 1.21 & 0.27 & 0.68 & 1.92 \\
\hline 9 & 466.87 & 1.41 & 0.00 & 16.39 & 2.01 & 0.19 & 0.61 & 2.10 \\
\hline 10 & 179.31 & 0.66 & 0.07 & 12.91 & 2.23 & 0.33 & 0.67 & 1.11 \\
\hline
\end{tabular}

395

396

\subsection{Indices of relative active tectonics (IRAT)}

397 In the present study, the morphometric indices consisting of linear and areal parameters and 398 the eight geomorphic indices are categorized into different classes and their average values are 399 considered for the evaluation of IRAT (Indices of relative active tectonics) (El Hamdouni et 400 al., 2008). The equation used for the calculation of IRAT is given as

$$
\mathrm{IRAT}=\left(\operatorname{Avg} \mathrm{Geo}+\operatorname{Avg} \_L n+\operatorname{Avg} A l\right) / n
$$

402 where Avg Geo, Avg_Ln, and Avg Al are average values of geomorphic indices, linear and 403 areal parameters class respectively and $n$ denotes the number of parameters.

404 Table 3 Classes of Morphometric Indices.

\begin{tabular}{|l|l|l|l|l|l|l|l|l|l|l|}
\hline \multirow{2}{*}{ Basin no } & \multicolumn{9}{|l|}{ Linear Parameters } & \multicolumn{6}{l|}{ Areal Parameters } \\
\cline { 2 - 10 } & Br & Lr & Avg_Ln & $F S$ & $D d$ & $D t$ & $C R$ & $F f$ & Avg Al \\
\hline 1 & 2 & 2 & 2 & 2 & 1 & 1 & 1 & 1 & 1.2 \\
\hline 2 & 3 & 2 & 2.5 & 3 & 1 & 3 & 1 & 1 & 1.8 \\
\hline 3 & 2 & 3 & 2.5 & 3 & 1 & 3 & 2 & 3 & 2.4 \\
\hline 4 & 3 & 1 & 2 & 2 & 2 & 3 & 1 & 2 & 2 \\
\hline 5 & 1 & 1 & 1 & 2 & 2 & 2 & 3 & 3 & 2.4 \\
\hline 6 & 2 & 3 & 2.5 & 2 & 1 & 1 & 1 & 1 & 1.2 \\
\hline 7 & 3 & 2 & 2.5 & 1 & 3 & 3 & 3 & 2 & 2.4 \\
\hline 8 & 1 & 3 & 2 & 2 & 3 & 2 & 2 & 3 & 2.4 \\
\hline 9 & 1 & 3 & 2 & 2 & 3 & 2 & 2 & 2 & 2.2 \\
\hline
\end{tabular}




\begin{tabular}{|l|l|l|l|l|l|l|l|l|l|}
\hline 10 & 3 & 2 & 2.5 & 1 & 3 & 2 & 3 & 3 & 2.4 \\
\hline
\end{tabular}

406 Table 4 Classes of geomorphic indices and calculation of IRAT.

\begin{tabular}{|l|l|l|l|l|l|l|l|l|l|l|l|l|l|}
\hline Basin & Sl & Vfh & Hi & Af & BS & $T$ & $B E$ & $S S$ & Avg Geo & Avg & Avg $A l$ & IRAT & Class \\
\hline 1 & 1 & 3 & 3 & 1 & 1 & 1 & 1 & 1 & 1.50 & 2 & 1.2 & 1.57 & 1 \\
\hline 2 & 3 & 2 & 1 & 2 & 3 & 1 & 1 & 2 & 1.88 & 2.5 & 1.8 & 2.06 & 2 \\
\hline 3 & 2 & 3 & 2 & 1 & 3 & 1 & 2 & 2 & 2.00 & 2.5 & 2.4 & 2.30 & 4 \\
\hline 4 & 3 & 2 & 1 & 2 & 3 & 2 & 2 & 1 & 2.00 & 2 & 2 & 2.00 & 2 \\
\hline 5 & 3 & 2 & 2 & 3 & 3 & 3 & 3 & 2 & 2.63 & 1 & 2.4 & 2.01 & 2 \\
\hline 6 & 2 & 3 & 1 & 2 & 1 & 1 & 1 & 2 & 1.63 & 2.5 & 1.2 & 1.78 & 1 \\
\hline 7 & 2 & 1 & 2 & 3 & 1 & 2 & 2 & 2 & 1.88 & 2.5 & 2.4 & 2.26 & 3 \\
\hline 8 & 1 & 3 & 2 & 2 & 3 & 2 & 3 & 3 & 2.38 & 2 & 2.4 & 2.26 & 3 \\
\hline 9 & 1 & 3 & 3 & 2 & 2 & 3 & 2 & 3 & 2.38 & 2 & 2.2 & 2.19 & 3 \\
\hline 10 & 2 & 1 & 3 & 2 & 2 & 2 & 3 & 1 & 2.00 & 2.5 & 2.4 & 2.30 & 4 \\
\hline
\end{tabular}

407

Finally, the values obtained for IRAT are further classified into four classes as Class 1,

409 Class 2, Class 3, and Class 4 representing very high, high, moderate, and low tectonic activity,

410 respectively (Hamdouni et al., 2008; Mahmood and Gloaguen, 2012; Anand and Pradhan, 2019; Taesiri et al., 2020). The lowest value of IRAT is 1.57 for Basin 1 and the highest value is 2.30 for Basin 3 and 10. The four classes for IRAT obtained in this study are Class 1 (1.57-

413 1.80) for very high, Class $2(1.81-2.06)$ for high, Class $3(2.07-2.26)$ for moderate, and Class $4144(2.27-2.30)$ for low tectonic activity (Fig. 11a). Basin 1 and 6 falls under class I covering an area about $47740 \mathrm{~km}^{2}$, a total area of $2507 \mathrm{~km}^{2}$ of basin 2, 4 and 5 lies in class 2, basin 7, 8 
and 9 falls under class 3 and it is comprised of total area $17495 \mathrm{~km}^{2}$ and class 4 consists of

417 basin 3 and 10 of total area $2090 \mathrm{~km}^{2}$ (Table 4).

418

419

420

421

422

423

424

425

426

427

428

429

430

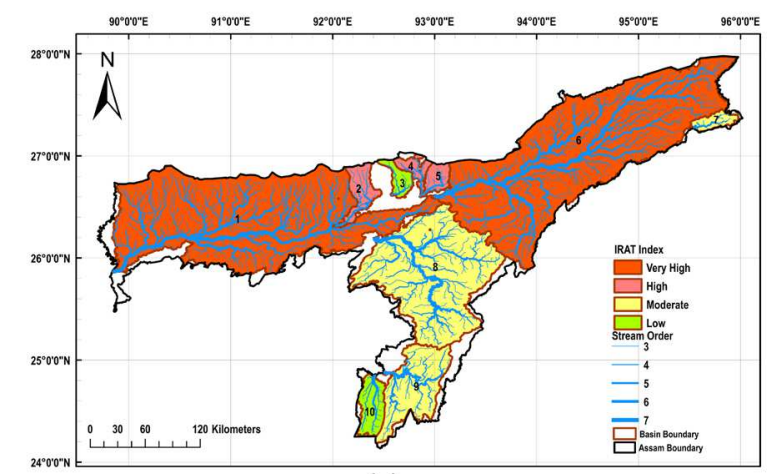

(a)

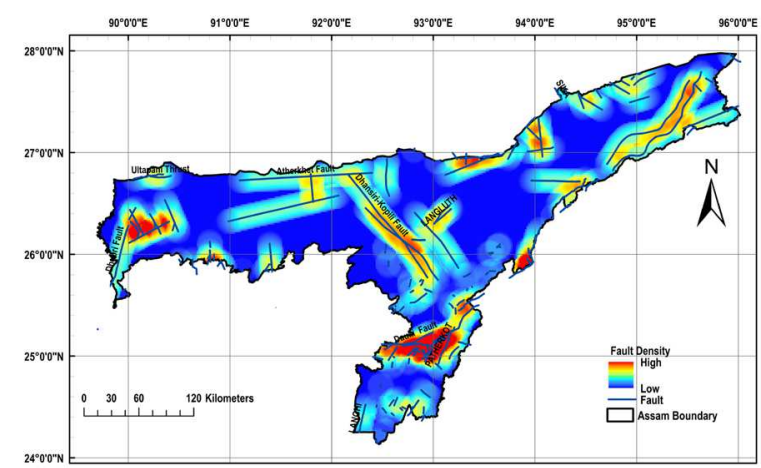

(b)

Fig. 11. Spatial distribution of (a) index of relative active tectonics (IRAT), and (b) fault density. 
The main aim of the study is the assessment, evaluation, and quantification of active

tectonics in the Assam region of India using the morphometric (two linear and five aerial parameters) and eight geomorphic indices. Finally, an IRAT distribution map is prepared and the entire study area is classified into four zones based on active tectonic. The results show that the basins are having consistent relations with their geometry, structural discontinuity, morphometric and geomorphic features.

\subsection{Linear and areal parameters}

In the present study, linear and areal parameters are evaluated on seven parameters for the ten basins. The stream order of the basins is determined and it is found that the stream order of the ten basins varies from $3^{\text {rd }}$ order to $7^{\text {th }}$ order (Fig. 5) (Strahler, 1952). With the increase in the order of streams the number of segments decreases, for example, the stream of $7^{\text {th }}$ order will have less number of a stream than $6^{\text {th }}$ order stream. The streams of lower order signify that the basin area is highly dissected. The basins $1,3,5,6,8$, and 9 which have higher value of Bifurcation ratio $(\mathrm{Br})$, major faults like Dhubri fault, Dhansiri Kopili fault, Kalyani shear, Dauki fault, Main Frontal thrust, Main Central thrust, Main Boundary thrust, Naga thrust, Bombdila fault, and Dudhnoi fault passes through it. Bifurcation ratio $(B r)$ and stream length ratio $(L r)$ are classified into three classes and it is found that $40,136 \mathrm{~km}^{2}$ of the area of basin falls under moderate tectonic activity zone, $29,009 \mathrm{~km}^{2}$ of the area lies in the low tectonic active zone and the high active tectonic zone constitutes $688 \mathrm{~km}^{2}$ of area. Similarly, an average of five areal parameters calculated in the study are classified into three zones, the area of the basin which comes under high, moderate, and low active tectonic zones are 48,948 $\mathrm{km}^{2}, 4,800$ $\mathrm{km}^{2}$, and $16,086 \mathrm{~km}^{2}$, respectively.

\subsection{Stream-length gradient index $(S l)$}

The values of the $S l$ index and longitudinal profile of the river show an increasing trend near the tectonically active zones. The values of stream-length gradient $(S l)$ index are 
quantified for all ten basins of the study area and it is found that the majority of the basin area falls under high to moderate zones i.e $39,525 \mathrm{~km}^{2}$ is under high (Class 1) and 27,801 $\mathrm{km}^{2}$ lies in the moderate zone (Class 2). These two classes of basins have several major faults passing through them or located in the vicinity of the basins. The total basin area of $2,507 \mathrm{~km}^{2}$ is classified as a low active tectonic zone (Class 3) with lower $S l$ values and it represents those streams are flowing through those areas having strike-slip faults (Dehbozorgi et al., 2010). The higher value of $S l$ signifies tectonic control of the basins have variable lithological contrast and thrusts (Sharma et al., 2018) and tectonic activities are the cause of higher $S l$ index values (Brookfield, 1998).

\subsection{Valley floor width to valley height Ratio (Vfh)}

The ratio of valley floor width to valley height $(V f h)$ identifies the presence of a tectonic process or erosional process in a basin. Lower the value of $V f h$ signifies the dominance of tectonic activity over the erosional process as result the shape of the valley is $\mathrm{V}$-shaped for the higher tectonic area and U-shaped for flat-floored valley or erosional process at bed level (Bull and McFadden, 1977). It is found that the lowest value of $V f h 0.26$ is obtained for basin 7 and the highest value is 8.54 for basin 1 , which indicates that the shape of basin 7 and basin 1 is comprised of V-and U- shaped valley respectively. The value of $V f h$ is less than 1 for basins $2,4,5,7$, and 10 indicating a V-shaped valley with a young stage of basin development. The $V f h$ value of basins $1,3,6,8$, and 9 is more than 1 and it denotes the predominance of erosional processes due to which broad U-shaped valleys are formed. The majority of the area i.e., 65,286 $\mathrm{km}^{2}$ of the area falls under U-shaped valleys or broad valleys and approximately $4,548 \mathrm{~km}^{2}$ of area represents a V-shaped valley.

\subsection{Hypsometric integral (Hi) and Hypsometric curve}

Hypsometric integral determines the total volume of the non-eroded basin and the hypsometric curve represents the developmental stages of a basin (Hamdouni et al., 2008). The 
Hi values calculated for the basins ranges from 0.002 to 0.287 signifies concave and convex curve respectively. In the present study, the shape of the hypsometric curve is mainly an Sshaped curve for basins 2, 4, 5, and 7 representing moderately eroded regions (Pedrera et al., 2009). Basins $1,3,6,8,9$, and 10 show a concave curve which indicates that the regions are highly eroded and fractured due to the presence of structural discontinuity and according to the fault map of the study area major faults are present in these basins. According to the shape of the hypsometric curves obtained for all the ten basins, it is evident that the basins belong to matured to older stages. The total area of the basin belongs to class 1 is $1,818 \mathrm{~km}^{2}$, Class 2 covers $14,652 \mathrm{~km}^{2}$ of area and $53,363 \mathrm{~km}^{2}$ of the area comes under Class 3 . It is found that the majority of the basin area is highly eroded and indicates the presence of faults and fractures or structural discontinuity.

\subsection{Asymmetric Factor $(A f)$}

The asymmetry factor of all ten basins is calculated to determine the tilting of the basin due to tectonic activity. If the value of $A f$ lies in the proximity of 50 then there will be no tilting and when the value of $A f$ is greater than or less than 50 tilting of the basin will occur due to the influence of active tectonics (Ahmad et al., 2018). In the present study, Basin 1 and 3 belongs to Class 1 (19.15-26.68) covering an area of $23,293 \mathrm{~km}^{2}$ and it is characterized as a highly tectonic zone due to the presence of major faults and thrusts like the Dhubri fault, Dhansiri Kopili fault, Main Frontal thrust, Main Boundary Thrust, and Dudhnoi fault. In Class 2 (11.1819.14), the basin $2,4,6,8,9$ and 10 falls under moderately active tectonic zones of $45,245 \mathrm{~km}^{2}$ area, and basin 5 and 7 belong to Class $3(<11.17)$ i.e., a low active zone covering a total area of $1,295 \mathrm{~km}^{2}$. It clearly states that the majority of the area falls under high to moderate active tectonic zones and it may be due to the presence of thrusts and faults passing through these basins.

\subsection{Drainage Basin shape index $(B S)$}



activity, so the basin shape index is calculated for the identification of tectonic activity of the basin. Generally, elongated basins are dominant in tectonic active regions whereas circular basins prevail in those regions which lack or exhibit low tectonic activity. The results of the study show a strong correlation of the shape of the basin with the presence of tectonic features like thrust, faults, or lineaments. The basin elongations are found in Basin 1, 6, and 7 and it belongs to Class 1 (2.45 -3.08) i.e high tectonic activity, covering an area of 48,347 $\mathrm{km}^{2}$. Major thrust, Main Central thrust, Main Boundary thrust, Bombdila fault, and Dudhnoi fault pass through Class 1 basins. The moderate active tectonic basins in Class $2(1.83-2.44)$, consisting of Basin 9 and 10 having a total area of $5,622 \mathrm{~km}^{2}$, belong to the Dauki fault and other structural discontinuity. Class $3(1.82-1.21)$ indicates the basins having low tectonic activity and Basin that the majority of the basin area falls under high tectonic activity according to the basin shape index.

\subsection{Transverse topographic symmetry $(T)$}

The values of transverse topographic symmetry $(T)$ are evaluated for the measurement of basin tilting due to tectonic activity and the value of $T=0$ for symmetric basin and $T>0$ for the asymmetric basin (Cox, 1994). In this study, basin 1, 2, 3, and 6 are grouped under Class 1 (0.38-0.54) of high active tectonics $\left(49,604 \mathrm{~km}^{2}\right.$ area), Basin $4,7,8$ and 10 belongs to moderate active tectonic zones $\left(15,351 \mathrm{~km}^{2}\right.$ area) i.e., Class $2(0.23-0.37)$ and Class $3(0.08-0.22)$ covers Basin 5 and 9 of low tectonic activity $\left(4,877 \mathrm{~km}^{2}\right.$ area).

\subsection{Basin Elongation ratio $(B E)$}

Basin elongation ratio indicates the recent tectonic activity of a drainage basin. Basins for which $B E$ values lie below 0.50 are considered as tectonically active areas, from 0.50 to 0.75 
are slightly active, and greater than 0.75 are inactive tectonic areas (Bull and McFadden, 1977).

In the present study, all the ten basins fall under active to slightly active class as the value ranges from 0.477 to 0.684 . Basin 1, 2, and 6 are represented as high tectonic active areas i.e., Class $1(0.477-0.502)$, and its total area is $48,948 \mathrm{~km}^{2}$, Class $2(0.503-0.664)$ signifies a moderately active zone consisting of Basin 3, 4, 7 and 9 with an area of approximately 6,063 $\mathrm{km}^{2}$. Basin 8 and 10 belongs to Class $3(0.665-0.684)$ contributing $14,133 \mathrm{~km}^{2}$ area.

\subsection{Stream Sinuosity $(S S)$}

Stream sinuosity index is also used as a proxy indicator for the assessment of tectonic activity. The high value of $S S$ signifies a tectonically stable river basin and the low value represents active basin area. In the present study, the range of the $S S$ index varies from 1.11 to 2.10. Basin 1,4 and 10 corresponds to low $S S$ value and therefore falls under Class 1 (1.11 1.17) of high tectonic zone $\left(24,681 \mathrm{~km}^{2}\right.$ area $)$, basin $2,3,5,6$ and 7 classified as moderate active zone $\left(28,264 \mathrm{~km}^{2}\right.$ area) i.e., Class $2(1.18-1.45)$ and Class $3(1.46-2.10)$ comprised of Basin 8 and 9 revealing low active zone $\left(16,888 \mathrm{~km}^{2}\right.$ area). According to the $S S$ index value, the majority of the area falls under the moderate tectonic activity zone category.

\subsection{Indices of relative active tectonics (IRAT)}

Previously, many studies have been performed on the assessment of relative tectonics based on geomorphic or morphotectonics parameters for a small stretch of a river basin, mountain front, smaller seismically active area, valleys of smaller area (Ahmad et., 2018; Anand and Pradhan, 2019; Bhat et al., 2020; Bhattacharjee and Mohanty, 2020; Taesiri et al., 2020 The present study is an attempt to investigate the spatial distribution of relative tectonics in Assam region $\left(78,438 \mathrm{~km}^{2}\right)$ by the application of geomorphic and morphometric indices on 
IRAT are classified into four classes as very high (Class 1), high (Class 2), moderate (Class 3), and low (Class 4) based on relative active tectonics (Fig. 11a) (Hamdouni et al., 2008).

The minimum and maximum values of IRAT obtained for the study area are 1.57 and 2.30 respectively. The IRAT class 1 covers Basin 1 and 6 with a total area of $47,740 \mathrm{~km}^{2}$, basin 2,4 and 5 lies in class 2 covering an area equal to 2,507 $\mathrm{km}^{2}$, class 3 consists of basin 7, 8 and 9 of $17,495 \mathrm{~km}^{2}$ in area and class 4 consists of basin 3 and 10 of total area $2090 \mathrm{~km}^{2}$. The present study area lies in the North-Eastern Himalayas and numerous studies have been conducted for different parts of the Himalayan region and its adjacent areas by the combined approach of two or more geomorphic indices to assess the relative tectonic in seismically active regions (Topal 2018; Anand and Pradhan 2019; Bahrami et al., 2020). A morphotectonic study conducted on tectonically active area NW Pakistan and NE Afghanistan, situated at the junction of Hindu Kush-Karakorum-Himalayas shows that the IRAT values range from 1.0 to 2.33 (Mahmood and Gloaguen, 2012). The geomorphic study conducted for Alborz province, located at the southern part of the Alborz Mountains (part of the Alps-Himalayan) shows that it is one of the seismic tectonic active areas with IRAT value ranging from 1.0 to 2.58. (Taesiri et al., 2020). The relative active tectonic assessment of the upper Ganga basin shows that the landform is greatly affected by neotectonic activity with IRAT values ranging from 1.50 to 2.38 (Anand and Pradhan, 2019).

In this study, Class 1 (Basin 1 and 6) and Class 2 (Basin 2, 4 and 5) of IRAT mainly lie along Dhubri fault, Dhansiri Kopili fault, Kalyani shear, Main Frontal thrust, Main Central thrust, Main Boundary thrust, Bombdila fault, and Dudhnoi fault. Basins of these two IRAT classes show the presence of neotectonic movements with high to a moderate value of stream length gradients, asymmetry valleys, elongated basins deviation of streams from the midline of the basins, stream sinuosity, and hypsometric integral. The basins of classes 1 and 2 represent mostly U-shaped valleys with moderate to low valley floor width to height ratio index. 
Very high to high IRAT values are along the mountain front, extending from west to

585

586

587

588

589

590

591

592

593

594

595

596

597

598

599

600

601

602

603

604

605

606

607

608

east of the study area and low to moderate IRAT values are found in central Assam and Barak valley. it also reveals that the tectonic activity of the region is not uniformly distributed which indicates the presence of a complex tectonic framework.

\section{Conclusion}

A GIS-based study of morphometric and geomorphic indices can be proved as useful tools in the evaluation or assessment of active tectonics of a region. The morphometric and geomorphic anomalies of an area can be studied by the application of these indices which are calculated from remote sensing data i.e. DEM data and GIS tool. The Assam region falls under seismic zone $\mathrm{V}$ with many major active faults and it had experienced great earthquakes in the past. The complex tectonic and geological framework of the Assam region makes it susceptible to seismic hazards. So, the method adopted in the present study is highly suitable for the analysis of active tectonic of the Assam region. The drainage network for the study area is derived from the DEM data of $30 \mathrm{~m}$ resolution and with the help of drainage data, morphometric indices (two linear and five areal parameters) and eight geomorphic indices are calculated for the ten delineated basins. Each index is classified into three active tectonic classes ranging from high (Class 1) to low (Class 3) and Index of relative active tectonics (IRAT) is evaluated by taking the average class value of linear, aerial, and geomorphic indices further grouped into four tectonic activity classes (from very high to low active tectonics).

Spatial distribution of IRAT shows a strong correlation with the structural discontinuity of the study area. The majority of the area falls under a very high to moderate active tectonic zone except for Basin 3 and 10 lie in the low tectonic activity zone. Basin 1 and 6 lie in a very high active tectonic zone with the presence of faults like Dhubri fault, Dhansiri Kopili fault, Kalyani shear, Main Frontal thrust, Main Central thrust, Main Boundary thrust, Bombdila fault, and Dudhnoi fault. Fault distribution map also supports the variation of IRAT in the study area 
and it correlates with asymmetric factor and transverse topographic symmetry of the basins. It

610

611

612

613

614

615

616

617 is evident from the results that morphometric indices (linear and areal parameters) have greatly influenced the tectonics of the study area as major faults and thrust like Dhubri fault, Dhansiri Kopili fault, Kalyani shear, Dauki fault, Main Frontal thrust, Main Central thrust, Main Boundary thrust, Naga thrust, Bombdila fault, and Dudhnoi fault passes through the basins. The $V f h$ indicates that the majority of the basin is U-shaped with the dominance of erosional processes. According to the values of asymmetric factor, it is found that most of the basins have structural discontinuity and influence of tectonic features like major faults and thrusts. Similarly, Sl, Hi, $A f, B S$, and $T$ show higher values in those basins where major faults and thrusts are present. Lower values of $B E$ and $S S$ are also considered as determining factors for the presence of active tectonics in the study area. The present study will help in determining the change of topography of the landform with the evolution of time and its influence on the occurrence of natural hazards like earthquakes, landslides, floods, etc. This study will also help in the identification of the hazard-prone area to have well-defined disaster management and mitigation policies and measures.

\section{CRediT authorship contribution statement}

Laxmi Gupta: Methodology, Formal analysis, Software, Resources, Investigation, Data curation, Validation, Visualization, Writing - Original Draft. Navdeep Agrawal: Data curation, Validation, Writing - Original Draft. Jagabandhu Dixit: Conceptualization, Methodology, Software, Resources, Supervision, Project administration, Writing - Review \& Editing. Subashisa Dutta: Writing - Review \& Editing.

\section{Declaration of interests}

The authors declare that they have no known competing financial interests or personal relationships that could have appeared to influence the work reported in this paper. 


\section{References}

634

1. Ahmad, S., Alam, A., Ahmad, B., Afzal, A., Bhat, M.I., Bhat, M.S., Ahmad, H.F. and Tectonics and Natural Hazards Research Group, 2018. Tectono-geomorphic indices of the Erin basin, NE Kashmir valley, India. Journal of Asian Earth Sciences, 151, pp.16-30.

2. Alizadeh, A., Moghadam, H.H. and Seraj, M., 2020. DEM-derived geomorphic indices for assessment of tectonic activity at the Dara anticlinal oil structure within the Zagros foldthrust belt, southwestern Iran. Arabian Journal of Geosciences, 13(4), pp.1-13.

3. Anand, A.K. and Pradhan, S.P., 2019. Assessment of active tectonics from geomorphic indices and morphometric parameters in part of Ganga basin. Journal of Mountain Science, 16(8), pp.1943-1961.

4. Bahrami, S., Capolongo, D. and Mofrad, M.R., 2020. Morphometry of drainage basins and stream networks as an indicator of active fold growth (Gorm anticline, Fars Province, Iran). Geomorphology, 355, p.107086.

5. Bahuguna, A. and Sil, A., 2020. Comprehensive seismicity, seismic sources and seismic hazard assessment of Assam, North East India. Journal of Earthquake Engineering, 24(2), pp.254-297.

6. Bhat, M.A., Dar, T. and Bali, B.S., 2020. Morphotectonic analysis of Aripal Basin in the North-Western Himalayas (India): An evaluation of tectonics derived from geomorphic indices. Quaternary International, 568, pp.103-115.

7. Bhattacharjee, N. and Mohanty, S.P., 2020. GIS-based approach for the measurement of variability in tectonomorphic signatures using DEM's data: a case study from the Habo Dome in the Kachchh area, India. Environmental Earth Sciences, 79(18), pp.1-26.

8. BhukoshGeological Survey of India URL: https://bhukosh.gsi.gov.in/Bhukosh/MapViewer.aspx (Last assessed: 20 May 2021). 
9. Biswas, M. and Paul, A., 2021. Application of geomorphic indices to Address the foreland Himalayan tectonics and landform deformation-Matiali-Chalsa-Baradighi recess, West Bengal, India. Quaternary International, 585, pp.3-14.

10. Bull, W.B., and McFadden, L.D., 1977. Tectonic geomorphology north and south of the Garlock fault, California. In: Doehring, D.O. (Ed.), Geomorphology in Arid Regions. Proceedings of the Eighth Annual Geomorphology Symposium. State University of New York, Binghamton, pp. 115-138.

11. Catherine, J.K., 2004. A preliminary assessment of internal deformation in the Indian Plate from GPS measurements. Journal of Asian Earth Sciences, 23(4), pp.461-465.

12. Cheng, W., Wang, N., Zhao, M. and Zhao, S., 2016. Relative tectonics and debris flow hazards in the Beijing Mountain area from DEM-derived geomorphic indices and drainage analysis. Geomorphology, 257, pp.134-142.

13. Cox, R.T., 1994. Analysis of drainage-basin symmetry as a rapid technique to identify areas of possible Quaternary tilt-block tectonics: An example from the Mississippi Embayment. Geological Society of America Bulletin, 106(5), pp.571-581.

14. Das, J.D., Shujat, Y. and Saraf, A.K., 2011. Spatial technologies in deriving the morphotectonic characteristics of tectonically active Western Tripura Region, Northeast India. Journal of the Indian Society of Remote Sensing, 39(2), pp.249-258.

15. Dawit, M., Olika, B.D., Muluneh, F.B., Leta, O.T. and Dinka, M.O., 2020. Assessment of Surface Irrigation Potential of the Dhidhessa River Basin, Ethiopia. Hydrology, 7(3), p.68.

16. Daxberger, H., Dalumpines, R., Scott, D.M. and Riller, U., 2014. The ValleyMorph Tool: An automated extraction tool for transverse topographic symmetry (T-) factor and valley width to valley height (Vf-) ratio. Computers \& Geosciences, 70, pp.154-163. 
680

17. Devi, R.M., 2008. Geomorphic appraisals of active tectonics associated with uplift of the Gohpur-Ganga section in Itanagar, Arunachal Pradesh, India. Geomorphology, 99(1-4), pp.76-89.

18. Divyadarshini, A. and Singh, V., 2019. Investigating topographic metrics to decipher structural model and morphotectonic evolution of the Frontal Siwalik Ranges, Central Himalaya, Nepal. Geomorphology, 337, pp.31-52.

19. Dixit, J., Raghukanth, S.T.G., Dash, S.K., 2016. Spatial Distribution of Seismic Site Coefficients for Guwahati City. In Geostatistical and Geospatial Approaches for the Characterization of Natural Resources in the Environment, Springer: Cham, Switzerland, pp. 533-537.

20. El Hamdouni, R., Irigaray, C., Fernández, T., Chacón, J. and Keller, E.A., 2008. Assessment of relative active tectonics, southwest border of the Sierra Nevada (southern Spain). Geomorphology, 96(1-2), pp.150-173.

21. Ghosh, B., Mukhopadhyay, S., Morishita, T., Tamura, A., Arai, S., Bandyopadhyay, D., Chattopadhaya, S. and Ovung, T.N., 2018. Diversity and evolution of suboceanic mantle: constraints from Neotethyan ophiolites at the eastern margin of the Indian plate. Journal of Asian Earth Sciences, 160, pp.67-77.

22. Gu, Z., Shi, C. and Peng, J., 2019. Evolutionary dynamics of the main-stem longitudinal profiles of ten kongdui basins within Inner Mongolia, China. Journal of Geographical Sciences, 29(3), pp.417-431.

23. Hack, J.T., 1973. Stream-profile analysis and stream-gradient index. Journal of Research of the US Geological Survey, 1(4), pp.421-429.

24. Hare, P.W. and Gardner, T.W., 1985. Geomorphic indicators of vertical neotectonism along converging plate margins, Nicoya Peninsula, Costa Rica. Tectonic Geomorphology, 4, pp.75-104. 
25. Horton, R.E., 1945. Erosional development of streams and their drainage basins; hydrophysical approach to quantitative morphology. Geological Society of America Bulletin, 56(3), pp.275-370.

26. ISC, International Seismological Centre, ISC-GEM Earthquake Catalogue 2021, URL: https://doi.org/10.31905/d808b825 (last accessed: 20 May 2021).

27. Khan, S., Fryirs, K.A. and Shumack, S., 2021. Semi-automating the calculation of catchment scale geomorphic controls on river diversity using publically available datasets. Catena, 203, p.105354.

28. Koukouvelas, I.K., Zygouri, V., Nikolakopoulos, K. and Verroios, S., 2018. Treatise on the tectonic geomorphology of active faults: The significance of using a universal digital elevation model. Journal of Structural Geology, 116, pp.241-252.

29. Latrubesse, E.M., 2008. Patterns of anabranching channels: The ultimate end-member adjustment of mega rivers. Geomorphology, 101(1-2), pp.130-145.

30. Longkumer, L., Luirei, K., Moiya, J.N. and Thong, G.T., 2019. Morphotectonics and neotectonic activity of the Schuppen Belt of Mokokchung, Nagaland, India. Journal of Asian Earth Sciences, 170, pp.138-154.

31. Mahmood, S.A. and Gloaguen, R., 2012. Appraisal of active tectonics in Hindu Kush: Insights from DEM derived geomorphic indices and drainage analysis. Geoscience Frontiers, 3(4), pp.407-428.

32. Mishra, M.N., 2019. Active tectonic deformation of the Shillong plateau, India: Inferences from river profiles and stream gradients. Journal of Asian Earth Sciences, 181, p.103904.

33. Mueller, J.E., 1968. An introduction to the hydraulic and topographic sinuosity indexes. Annals of the Association of American Geographers, 58(2), pp.371-385.

34. Panda, D., Kundu, B. and Santosh, M., 2018. Oblique convergence and strain partitioning in the outer deformation front of NE Himalaya. Scientific Reports, 8(1), pp.1-9. 
35. Pei, Y., Qiu, H., Hu, S., Yang, D., Zhang, Y., Ma, S. and Cao, M., 2021. Appraisal of tectonic-geomorphic features in the Hindu Kush-Himalayas. Earth and Space Science, p.e2020EA001386.

36. Raghukanth, S., Dixit, J., Dash, S., 2011. Ground motion for scenario earthquakes at Guwahati city. Acta Geod. Geophys. Hung., 46, 326-346.

37. Raj, R., 2012. Active tectonics of NE Gujarat (India) by morphometric and morphostructural studies of Vatrak River basin. Journal of Asian Earth Sciences, 50, pp.66-78.

38. Ramírez-Herrera, M.T., 1998. Geomorphic assessment of active tectonics in the Acambay Graben, Mexican volcanic belt. Earth Surface Processes and Landforms: The Journal of the British Geomorphological Group, 23(4), pp.317-332.

39. Rodríguez, M.O.C., Barba, D.C. and Escribano, D.N., 2017. Morphotectonic study of the Greater Antilles. Geotectonics, 51(1), pp.89-104.

40. Saber, R., Caglayan, A. and Isik, V., 2018. Relative tectonic activity assessment and kinematic analysis of the North Bozgush fault Zone, NW Iran. Journal of Asian Earth Sciences, 164, pp.219-236.

41. Saber, R., Isik, V. and Caglayan, A., 2020. Tectonic geomorphology of the Aras drainage basin (NW Iran): Implications for the recent activity of the Aras fault zone. Geological Journal, 55(7), pp.5022-5048.

42. Sarp, G. and Duzgun, S., 2015. Morphometric evaluation of the Afşin-Elbistan lignite basin using kernel density estimation and Getis-Ord's statistics of DEM-derived indices, SE Turkey. Journal of Asian Earth Sciences, 111, pp.819-826.

43. Schumm, S.A., 1956. Evolution of drainage systems and slopes in badlands at Perth Amboy, New Jersey. Geological Society of America Bulletin, 67(5), pp.597-646. 
44. Sharma, S. and Sarma, J.N., 2017. Application of drainage basin morphotectonic analysis for assessment of tectonic activities over two regional structures of northeast India. Journal of the Geological Society of India, 89(3), pp.271-280.

45. Shukla, D.P., Dubey, C.S., Ningreichon, A.S., Singh, R.P., Mishra, B.K. and Singh, S.K., 2014. GIS-based morpho-tectonic studies of Alaknanda river basin: a precursor for hazard zonation. Natural Hazards, 71(3), pp.1433-1452.

46. Silalahia, F.E.S. and Hidayatb, F., 2019. Modelbuilder and Unit Hydrograph for Flood Prediction and Watershed Flow Direction Determination at the West Branch of the Little River, Stowe, Lamoille County, Vermont, USA. Geoplanning: Journal of Geomatics and Planning, 6(2), pp.89-98.

47. Silva, P.G., Goy, J.L., Zazo, C. and Bardaj1, T., 2003. Fault-generated mountain fronts in southeast Spain: geomorphologic assessment of tectonic and seismic activity. Geomorphology, 50(1-3), pp.203-225.

48. Singh, Y. and Chaudhri, A.R., 2020. Morphotectonic Study of Frontal Siwalik Hills, near Gandhiri, Kangra, Himachal Pradesh, India. Open Journal of Geology, 10(04), p.280.

49. Sreedevi, P.D., Subrahmanyam, K. and Ahmed, S., 2005. The significance of morphometric analysis for obtaining groundwater potential zones in a structurally controlled terrain. Environmental Geology, 47(3), pp.412-420.

50. Strahler, A.N., 1952. Hypsometric (area-altitude) analysis of erosional topography. Geological Society of America Bulletin, 63(11), pp.1117-1142.

51. Taesiri, V., Pourkermani, M., Sorbi, A., Almasian, M. and Arian, M., 2020. Morphotectonics of Alborz Province (Iran): A Case Study Using GIS Method. Geotectonics, 54(5), pp.691-704.

52. Topal, S., 2018. Quantitative analysis of relative tectonic activity in the Acıgöl fault, SW Turkey. Arabian Journal of Geosciences, 11(9), pp.1-10. 
53. USGS EARTH EXPLORER URL: https://earthexplorer.usgs.gov/ (last accessed: 22 May 2021).

54. USGS NEIC. US Geological Survey National Earthquake Information Centre 2021, URL: http://earthquake.usgs.gov/earthquakes (last accessed: 20 May 2021).

55. Zhang, T., Fan, S., Chen, S., Li, S. and Lu, Y., 2019. Geomorphic evolution and neotectonics of the Qianhe River Basin on the southwest margin of the Ordos Block, North China. Journal of Asian Earth Sciences, 176, pp.184-195. 